\title{
Influence of curing age on the mechanical properties of fly ash concrete
}

\author{
exposed to elevated temperature \\ Qingtao Li ${ }^{\text {a,c }}$, Limin Lu ${ }^{\text {a,b }}$, Guanglin Yuan ${ }^{a}$, Jeung-Hwan Doh ${ }^{\text {d }}$ \\ aJiangsu Key Laboratory of Environmental Impact and Structural Safety in Engineering, \\ China University of Mining \& Technology, Xuzhou, Jiangsu, 221116, China

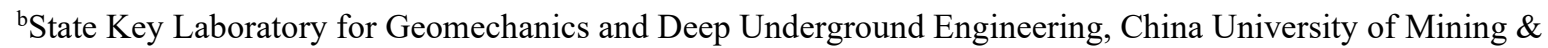 \\ Technology, Xuzhou, 221116, China \\ 'Jiangsu Collaborative Innovation Center for Building Energy Saving and Construction Technology, Xuzhou, \\ Jiangsu 221116, China \\ ${ }^{\mathrm{d}}$ School of Engineering and Built Environment, Griffith University, QLD, 4222, Australia \\ *Correspondence; Jeung-Hwan Doh, School of Engineering and Built Environment, Griffith University, QLD, \\ 4222, Australia \\ Email: j.doh@griffith.edu.au
}

\begin{abstract}
The mechanical properties of early-age fly ash (FA) concrete was experimentally studied. The splitting tensile strength and compressive strength under different curing ages, temperatures, cooling methods and FA contents were analyzed. The experimental results showed that the splitting tensile strength of concrete increased proportionally with temperature in the early stage and decreased as the temperature further increased. Compared to the concrete with FA content of $10 \%$ and $30 \%$, the compressive strength of concrete with FA content of $20 \%$ was found to be highest at the age of $90 \mathrm{~d}$. The strength of the specimens under water cooling was comparatively lower than that under air cooling. The compressive strength of FA concrete heated to $150{ }^{\circ} \mathrm{C}$ was greater than that of the unheated concrete. The compressive strength of FA concrete heated to $550{ }^{\circ} \mathrm{C}$ was lower than that of concrete without treatment at high temperature. After high temperature exposure at the age of $90 \mathrm{~d}$, the compressive strength of the specimen was higher than that of the specimens at the ages of $7 \mathrm{~d}, 14 \mathrm{~d}$ and $28 \mathrm{~d}$. The microstructures of the specimens aged 90 days were measured by the SEM method before and after being exposed to high temperatures.
\end{abstract}

Keywords: early age; temperature-related \& thermal effects; fly ash; concrete 


\section{INTRODUCTION}

With the increasing application of FA (fly ash) concrete in many concrete structures, FA concrete in construction industries has been reported. ${ }^{[1-6]}$ In order to make better use of FA concrete, its fire resistance must be studied. The maximum tolerable temperature of FA concrete is $400{ }^{\circ} \mathrm{C}$, after that it has a lower plastic deformation capacity than ordinary concrete. ${ }^{[7-8]}$ When the temperature exceeds $400{ }^{\circ} \mathrm{C}$, FA concrete show a huge loss in compressive strength. In comparison to natural cooling, the compressive strength of the specimen is reduced when using the water-spraying cooling process. ${ }^{[9]}$ Therefore, the addition of FA can effectively improve the compressive strength of ordinary concrete, and can slow down the cracking of the concrete in high temperature conditions. ${ }^{[10]}$ It has been reported that the effect of the cooling method on the properties of concrete is reduced with increasing FA content. ${ }^{[11]}$ In comparison to air cooling, water cooling leads to a larger reduction in the compressive strength of the specimen after exposure to elevated temperatures. In general, fly ash can effectively enhance the workability, compactness and fire-resistance of concrete.

In recent years, because of the widely accepted applications of concrete, the mechanical properties of early-age concrete after fire damage has attracted increasing attention. The hydration reaction in early-age concrete is generally not fully completed, therefore the internal compositions are in an active state of change. ${ }^{[12]}$ During this period, the hydration reaction rate and hydration degree inside the concrete is affected by many factors such as temperature, high temperature duration, extinguishing method and later curing time. Therefore, the residual properties of concrete at an early age is very different from that concrete at an adequate age. ${ }^{[13-}$ ${ }^{14]}$ When the concrete was heated to a high temperature after 3 days and continued to be cured to the $28^{\text {th }}$ day, most of its compressive strength could be recovered. The recovery of compressive strength of concrete cooled by water is more evident. ${ }^{[13]}$ Increasing the usage of FA can effectively improve the compressive strength of concrete. FA concrete requires a longer curing time than ordinary concrete without FA. ${ }^{[15]}$ The mechanical properties of early-age FA concrete begin to increase after being cured for $28 \mathrm{~d}^{[16-17]}$ analysed the hydration and mechanical properties of high-volume slag and fly ash concrete at different curing temperatures. The results showed that high volume fly ash accelerated the cement hydration at an early age because of 
the dilution and filler effects. The hydration process of fly ash concrete was also more sensitive to temperature. The results of ${ }^{[18]}$ showed that it was important to consider the temperature effect on concrete creep and tensile strength when the temperature variation in concrete was significant at very early ages. However, there is limited research on the mechanical properties of early-age fly ash concrete, especially under the influence of elevated temperatures.

This paper discusses experimental research on the material strength of FA concrete under elevated temperatures. The splitting tensile strength and compressive strength under different curing ages, temperatures, cooling methods and FA contents will be analyzed.

\section{RESEARCH SIGNIFICANCE}

Fire accidents during the construction period of concrete structures occur occasionally. Once a fire accident occurs during the construction period, the mechanical properties of the concrete that has not yet reached its actual design strength will be significantly changed, which may result in serious security risks for the whole structure. When the concrete is exposed to high temperature before the FA and cement in the concrete has been fully hydrated, the mechanical properties of FA concrete will be different to the unheated FA concrete. Therefore, it is of great practical significance to study the performance of FA concrete that is heated at early ages. It is very important to evaluate the safety of concrete structures affected by high temperature during the construction period.

\section{OVERVIEW OF EXPERIMENT 3.1 Materials and specimens}

Cement produced by Huaihai Cement Plant was used in this study, and its grade was PO.42.5. The composition of the cement is shown in Table 1. Fly ash discharged by Pengcheng power Plant in Xuzhou was used. Its fineness (weight of screen residue by $45 \mu \mathrm{m}$ square holes) was up to $10 \%$ with an ignition loss of $3 \%$ and a water content ratio of $92 \%$. The ingredients and parameters for FA are listed in Table 2 and Table 3. River sand was applied as fine aggregates, while gravel was used as coarse aggregates. In order to make the concrete consistent with the concrete used in actual projects, the mix proportion was designed based on the 
specification concrete. ${ }^{[19]}$

\subsection{Grouping of specimens}

The amount of FA used in concrete was calculated according to $\mathrm{MOC}^{[20]}$. The mix proportion of FA concrete is listed in Table 4.

The damage of concrete treated at temperatures above $600{ }^{\circ} \mathrm{C}$ is serious and the compressive strength decreases significantly ${ }^{[7]}$, it is better to be chiseled. There is no significance at this stage for repair. Therefore, in this study the specimens were heated up to only $150^{\circ} \mathrm{C}, 350^{\circ} \mathrm{C}$ and $550^{\circ} \mathrm{C}$. Because the early strength of FA concrete is low, the secondary hydration reaction generally starts after 14 days of concrete casting. The active effect of fly ash is still at the initial stage after curing for $28 \mathrm{~d}^{[21]}$ In addition, according to the determination of design age of fly ash concrete given by Nadem et al. ${ }^{[9]}$, it is mandatory to consider the type of building and the actual loading time. Further, contribution of FA to the concrete strength in later periods, which should be $28 \mathrm{~d}$ or $60 \mathrm{~d}$ for aboveground and ground construction, and $60 \mathrm{~d}$ or $90 \mathrm{~d}$ for underground construction. Therefore, in this study the specimens were cured for $7 \mathrm{~d}, 14 \mathrm{~d}$, $28 \mathrm{~d}, 60 \mathrm{~d}$ and $90 \mathrm{~d}$, respectively before the high temperature treatments. By combining it with the fire extinguishing methods utilised when a fire occurs in buildings, two cooling methods (natural cooling and water-spraying cooling) are also used.

For FA concrete, cubes of $100 \mathrm{~mm} \times 100 \mathrm{~mm} \times 100 \mathrm{~mm}$ were prepared, and the mold was removed after $24 \mathrm{~h}$ of pouring. The specimens were put in the curing chamber at a temperature of $20 \pm 2{ }^{\circ} \mathrm{C}$ and R.H. above $90 \%$ for $7 \mathrm{~d}, 14 \mathrm{~d}, 28 \mathrm{~d}, 60 \mathrm{~d}$ and $90 \mathrm{~d}$, respectively. Afterwards, the specimens were taken out to carry out heating tests. The specimens were tested under the conditions within Table 5.

\subsection{Experiment equipment}

A hydraulic pressure testing machine of WE-1000A type is used for loading with the loading speed controlled at $5 \mathrm{kN} / \mathrm{s}^{[22]}$. The electric furnace whose power is $30 \mathrm{~kW}$ is used for heating with internal net size of $2000 \mathrm{~mm} \times 600 \mathrm{~mm} \times 400 \mathrm{~mm}$.

The heating rate was fixed at $10{ }^{\circ} \mathrm{C} / \mathrm{min}$. In order to make the temperature field uniform 
within the specimens, the specimens were maintained at the target temperature for $90 \min ^{[23]}$ and then they were brought out to cool to room temperature. The splitting tensile strength and compressive strength of concrete were measured in accordance with the manual of specification of concrete. ${ }^{[22]}$

\section{RESULTS AND DISCUSSION}

The compressive strength of the FA specimens which were heated at high temperatures at different curing ages are listed in Table 6. Table 6 shows that the concrete with $20 \%$ fly ash content displayed better compressive strength at normal temperatures. Therefore, it was selected for the splitting tensile strength experiment. The splitting tensile strengths of FA concrete at different curing ages after being exposed to elevated temperatures are listed above in Table 7.

\subsection{Compressive strength of FA concrete}

\subsubsection{Effect of high temperature on the compressive strength}

The strength of the naturally cooling concrete containing no FA increases at $150{ }^{\circ} \mathrm{C}$. After being treated at $350{ }^{\circ} \mathrm{C}$ at ages of $7 \mathrm{~d}$ and $14 \mathrm{~d}$, the concrete strength increases, while it decreases significantly after being treated at $550{ }^{\circ} \mathrm{C}$. The concrete strength increases after being treated at $150{ }^{\circ} \mathrm{C}$ at curing ages of $28 \mathrm{~d}, 60 \mathrm{~d}$ and $90 \mathrm{~d}$, while the compressive strength shows a decrease when the temperature reached $550{ }^{\circ} \mathrm{C}$.

As shown in Fig. 1 (a), the strength of the specimens without FA show an enhancement of $19.81 \%$, when the specimens were heated to $150{ }^{\circ} \mathrm{C}$ after being cured for $7 \mathrm{~d}$. While the compressive strength of concrete was increased by $30.02 \%$ when the specimens were heated to $350{ }^{\circ} \mathrm{C}$. However, a decrease of $15.18 \%$ is reported when the specimens were heated to $550{ }^{\circ} \mathrm{C}$.

For the naturally cooled FA concrete as shown in Fig. 1 (c), (e) and (g), the compressive strengths of concrete heated to $150{ }^{\circ} \mathrm{C}$ at curing ages of $7 \mathrm{~d}$ and $14 \mathrm{~d}$ are greater than those of the unheated specimens. While, the strength of FA concrete decreases if the specimens were treated at $350^{\circ} \mathrm{C}$ and $550{ }^{\circ} \mathrm{C}$. After exposure to $150{ }^{\circ} \mathrm{C}$ and $350^{\circ} \mathrm{C}$ at curing ages of $28 \mathrm{~d}, 60 \mathrm{~d}$ and $90 \mathrm{~d}$, the compressive strength of FA concrete increase significantly. After exposure to $550{ }^{\circ} \mathrm{C}$, the compressive strength is significantly lower than that of the concrete without treatment to high temperature. 
For the concrete exposed to $150^{\circ} \mathrm{C}$ at early ages, the internal cement hydration reaction is not finished. High temperature treatment promotes the continuing hydration of unhydrated cement particles leading to an increase in the hydration process and products. ${ }^{[15]}$ At the same time, the dehydration reaction of C-S-H gel occurs due to the evaporation of free water, which causes hardening of the cement slurry, and an increase in both the chemical binding forces and the compressive strength. ${ }^{[24]}$

After exposure to $350{ }^{\circ} \mathrm{C}$, the free water in concrete begins to evaporate, and part of the crystal water begins to decompose due to high temperatures. The evaporation of pore water and chemical-bound water results in increasing porosity in the cement slurry. Due to the relatively low hydration degree of FA in concrete at curing ages less than 28d, the damage in concrete caused by the high temperature is more significant than the improvement in strength caused by the accelerated hydration of cement due to high temperature. Therefore, the strengths of specimens heated at ages of $7 \mathrm{~d}$ and $14 \mathrm{~d}$ were lower than that of the unheated concrete. On the other hand, after being exposed to $350{ }^{\circ} \mathrm{C}$ at curing ages of $28 \mathrm{~d}, 60 \mathrm{~d}$ and $90 \mathrm{~d}$, the cement will have completed most of the hydration reaction and the internal structure will be intact ${ }^{[28]}$, which may cause an enhancement in compressive strength.

After exposure to $550{ }^{\circ} \mathrm{C}$, the concrete completely loses its free water, pore water and crystal water. At $550{ }^{\circ} \mathrm{C}$, and the gap increases as the $\mathrm{Ca}(\mathrm{OH})_{2}$ starts to decompose. The differences of thermal expansion performance cause the development of cracks between the aggregate and cement stone. The increase in the number and width of the cracks cause macroscopic damages and a rapid decrease in concrete strength. ${ }^{[26]}$

\subsubsection{Effect of cooling method on the compressive strength}

From Fig. 2, it can be determined that the compressive strength of the water-spraying cooled specimen is smaller than that of the naturally cooled specimens when the FA concrete was heated to high temperature at different curing ages. It also shows that the decreasing rate increases with the increasing temperature.

In Fig. 2 (c), taking the concrete with FA content of $20 \%$ as an example, the influence of the cooling method on the residual compressive strength was significant. For FA20 concrete subjected to 150,350 and $550{ }^{\circ} \mathrm{C}$ at a curing age of $7 \mathrm{~d}$, the compressive strength of water- 
spraying cooled specimens was reduced by $6.96 \%, 12.7 \%$ and $17.07 \%$ compared to that of naturally cooled concrete. While the compressive strength of FA0 concrete cooled by waterspraying was reduced by $4.86 \%, 9.75 \%$ and $15.48 \%$, respectively as compared to the naturally cooled specimens when subjected to 150,350 and $550{ }^{\circ} \mathrm{C}$ temperatures. At the curing age of 90d, after the FA20 concrete specimens were heated at 150,350 and $550{ }^{\circ} \mathrm{C}$, the compressive strength of the water-spraying cooled specimens was reduced by $7.49 \%, 10.4 \%$ and $14.9 \%$, respectively as compared to the naturally cooled specimens.

The sudden drop of temperature caused by spraying water, uneven thermal expansion and contraction cause the formation of multiple cracks in the concrete, which results in a decrease in the compressive strength. After being treated at 150 and $350{ }^{\circ} \mathrm{C}$, the expansion defomrations of aggregate and gel were small. Due to stress, the differences in the compressive strength of naturally cooled and water-spraying cooled concrete were small. However, after treatment at $550^{\circ} \mathrm{C}$, the differences in expansion of aggregate and gel were greater. The difference in the volume change is found to be incongruous in between the aggregate and slurry, which leads to the formation of more cracks. The formation of micro-cracks damages the cementation between the aggregate and slurry, which results in a reduction of the compressive strength. ${ }^{[1]}$

\subsubsection{Effect of FA on the compressive strength}

Fig. 3 shows that the variation in the compressive strength of concrete with different fly ash content were similar to each other at the same curing time.

For the concrete subjected to high temperature at curing ages of $7 \mathrm{~d}, 14 \mathrm{~d}$ and $28 \mathrm{~d}$, the high content of FA reduces the residual strength. The main reason for this is that the proportion of cement clinker minerals decreases after the addition of FA in the early stages of hydration, which results in the decrease of hydration products in the concrete. The addition of FA also causes a decrease in the $\mathrm{Ca}^{2+}$ concentration in the solution and the total hydration rate in the cement-FA system. Since the hydration degree is very low, the particle connection between the generated hydration products is not close enough, which causes an increase in the total porosity and a decrease in the compactness of the hydrate. Therefore, the concrete with high content of FA have a lower compressive strength.

For the concrete specimens subjected to high temperatures at $60 \mathrm{~d}$ and $90 \mathrm{~d}$, the compressive 
strength of concrete containing fly ash contents of $10 \%$ and $20 \%$ was found to be much greater than that of concrete containing no FA. The strength of the concrete specimens with FA content of $20 \%$ was found to be the highest. Because the effective water to cement ratio of cement clinker in the specimen with FA was relatively large, the hydration of the cement clinker is fast and the secondary hydration reaction of FA occurs. FA particles with smaller particle size than cement particles fill the pore spaces and reduce the porosity of the FA concrete, so the internal microstructure was found to be much denser than the standard concrete, which cause an increase in the compressive strength ${ }^{[2]}$.

Nevertheless, the compressive strength of concrete with FA content of $30 \%$ was found to be lower than that of the concrete with FA contents of $10 \%$ and $20 \%$. The main reason is that when the FA content is too much, the calcium hydroxide content, which plays the excitation role in the concrete, becomes too small. This causes a large decrease in the FA hydration conditions, which is not conducive to the development of later compressive strength.

\subsubsection{Effect of curing age before high temperature on the compressive strength}

From Fig. 4, it can be determined that the compressive strength of FA concrete increases with an increase in curing age before heating. The increase in compressive strength of specimens containing FA is more significant than that of the specimens without FA.

Under high temperature at curing ages of $7 \mathrm{~d}$ and $14 \mathrm{~d}$, FA has almost not contribution to the hydration reaction. As part of the cement is replaced by FA, the proportion of minerals in the cement clinker decreases, which cause a reduction of hydration products. The hydration product particles are not tightly connected and the microstructure is loose. Therefore, the compressive strength reduced following the high temperature treatment.

For the concrete subjected to high temperature at $28 \mathrm{~d}$, the hydration reaction of fly ash is still occurring, and so the filling effect of FA particles and aggregate helps in establishing a cross connection among the hydration products. At this stage, there is a decrease in porosity and an increase in the structural density at $7 \mathrm{~d}$ and $14 \mathrm{~d}$, which causes a significant enhancement in the compressive strength.

Exposure to high temperature at the age of $60 \mathrm{~d}$ causes the porosity of hydrates in the concrete to be further reduced and therefore the structure becomes dense, so the compressive 
strength of FA concrete is increasing. But the activity of FA at this time has not yet fully developed, and there exist gaps between the FA particles and cement gel; FA is required for further hydration of the gel.

With the increase in curing age, the increase in the compressive strength of FA concrete after high temperature treatment at $90 \mathrm{~d}$ is clear, and the secondary hydration effect of FA happens to produce more C-S-H gel. At the same time, the FA particles with smaller particle size than the cement particles fill up the pores of the concrete and reduce the porosity of the FA concrete. This cause densification and compactness of the internal microstructure of the concrete and helps in increasing the compressive strength of concrete.

\subsection{Splitting tensile strength of FA concrete}

\subsubsection{Effect of high temperature on the splitting tensile strength}

Fig. 5 shows the splitting tensile strength residue rate of FA concrete with different curing ages and different fly ash content after being exposed to temperatures of $150{ }^{\circ} \mathrm{C}, 350{ }^{\circ} \mathrm{C}$ and $550^{\circ} \mathrm{C}$. From Fig. 5 , it can be seen that the changing rule of FA concrete under air cooling and water cooling after exposure to elevated temperatures was similar, but the regularity differed between concrete of different curing ages. From the comparison between FB0 and FB20, it can also be seen that the changing rule of the splitting tensile strength of FA concrete after exposure to elevated temperatures was different in normal concrete.

For specimens aged less than 28 days, in which the hydration reaction is not finished, the temperature promoted further hydration. Therefore, the splitting tensile strength of each sample increased with higher temperatures. Moreover, the strength residue rate of normal concrete after exposure to elevated temperatures was larger than that of fly ash concrete.

The hydration reaction of the samples aged more than 28 days was nearly finished. When exposed to a temperature of $150^{\circ} \mathrm{C}$, the precipitation of free water inside the concrete and the intermediary water of C-S-H damaged the internal structure of the concrete, leading to a reduction of the splitting tensile strength. For the concrete samples exposed to a temperature of $350^{\circ} \mathrm{C}$, the damage to the microstructure of the concrete was stable, and the splitting tensile strength reduced slowly. After the sample was exposed to a temperature of $550^{\circ} \mathrm{C}$, the chemical components decomposed. The C-S-H gel and a large quantity of $\mathrm{CaO}$ broke down, leading to a 
1 sharp decline in concrete strength. ${ }^{[27]}$ Compared with normal concrete, the fly ash of the FA concrete continued to react after the hydration of the cement was finished. At curing ages of more than 28 days, due to the better fire-resistance properties of fly ash, the splitting tensile strength of the FA concrete at elevated temperatures was higher than that of normal concrete. This conclusion agrees with that reported by Mendes et al. ${ }^{[28]}$

\subsubsection{Influence of cooling method on the splitting tensile strength of FA concrete}

Comparisons of the splitting tensile strength residual rate of FA concrete exposed to high temperatures and cooled by either air or water are shown in Fig. 6.

From Fig. 6, it can be seen that the splitting tensile strength of concrete exposed to high temperatures followed by water cooling was lower than that followed by air cooling. This difference was greater with increasing temperatures. Fig. 6(b) shows that, for the FA concrete aged 7 days with $20 \%$ fly ash content, the remaining splitting tensile strength of the specimen under water cooling was $7.32 \%, 12.8 \%$ and $12.9 \%$ less than that under air cooling after being exposed to temperatures of $150^{\circ} \mathrm{C}, 350^{\circ} \mathrm{C}$ and $550^{\circ} \mathrm{C}$ respectively. It can be concluded that the strength difference between the concrete under the two cooling methods increased with higher temperatures.

When exposed to a temperature of $150^{\circ} \mathrm{C}$, the splitting tensile strength of FA concrete under air cooling increased within a small range. This was because the dehydrated fly ash and cement particles reacted to form calcium silicate hydrates. For the specimens under water cooling, some of the samples were partly strengthened and partly reduced before heating. Water cooling supplemented the water that had evaporated and promoted further hydration inside the concrete. However, water cooling also led to a severe temperature change on the surface of the specimen, which caused cracking inside the concrete.

With increasing temperatures, the influence of the cooling method on the splitting tensile strength tended to be stronger. The strength difference between the concrete under the two cooling methods increased with temperature. As water cooling led to a large temperature gradient on the surface of the specimen, cracking was accelerated. The temperature difference on the surface increased and the cracking was more severe when the specimen was exposed to a higher temperature. Therefore, the remaining strength of the FA concrete was much lower. 
Elevated temperatures made the components of the concrete expand or shrink, which led to uncoordinated deformation. Moreover, the $\mathrm{Ca}(\mathrm{OH})_{2}$ dehydrated into $\mathrm{CaO}$ when the temperature of the concrete exceeded $400^{\circ} \mathrm{C}$. This made the concrete shrink and crack. If the water cooling method was applied, the $\mathrm{CaO}$ quickly absorbed water and rehydrated into $\mathrm{Ca}(\mathrm{OH})_{2}$. The reexpansion of the cement made the ionic compounds decompose into smaller particles which led to sharp decreases in the splitting tensile strength.

\subsubsection{Influence of curing age on the splitting tensile strength of FA concrete}

The tensile strength of FA concrete after exposure either to elevated temperatures or to normal temperature $\left(20^{\circ} \mathrm{C}\right)$ was compared and analyzed. In this paper, this is designated the splitting tensile strength residue rate.

From Fig. 7 it can be seen that the longer the curing age, the higher the splitting tensile strength of the FA concrete. The magnitude of the strength increase for fly ash concrete was much greater than that of normal concrete without fly ash.

For FA concrete aged 7 and 14 days and exposed to elevated temperatures, the fly ash did not participate in the hydration reaction. As the content of cement was reduced by the addition of extra fly ash, the hydration product was also reduced.

For FA concrete aged 28 days and exposed to elevated temperatures, the porosity in the concrete was reduced because of the hydration reaction of the fly ash. The splitting tensile strength was much greater than that of the FA concrete aged 7 and14 days.

For FA concrete aged 56 days and exposed to elevated temperatures, the porosity between the hydration production was reduced and the microstructure became denser, leading to an increase in the splitting tensile strength of the FA concrete. However, the fly ash had not fully reacted. It needed further hydration.

The specimen aged 90 days and exposed to elevated temperatures exhibited the highest splitting tensile strength. The secondary hydration of the fly ash produced a large amount of C$\mathrm{H}-\mathrm{S}$ gel. Moreover, as the fly ash particles were smaller than that of the cement particles, they could effectively fill the pores, making the microstructure of the concrete much denser.

\subsection{Analysis of microstructures of FA concrete}


The microstructures of the specimens aged 90 days were measured by the SEM method before and after being exposed to high temperatures, as shown in Fig. 8 below.

From Fig. 8 and Fig. 9, it can be seen that the microstructure of the FA concrete was not dense. There was obvious cracking, which greatly reduced the contact area of the hydration products. This contributed to the conclusion that the splitting tensile strength of concrete under water cooling was comparatively lower than that under air cooling.

After the samples were exposed to temperatures of $150^{\circ} \mathrm{C}$ or $350^{\circ} \mathrm{C}$, the $\mathrm{C}-\mathrm{H}$ of the $\mathrm{FA}$ concrete decreased, and the secondary reaction of fly ash was more significant meaning that $150^{\circ} \mathrm{C}$ and $350^{\circ} \mathrm{C}$ promoted the hydration of fly ash and cement. Therefore, the splitting tensile strength of FA concrete aged 90 days slightly increased after being exposed to temperatures of $150^{\circ} \mathrm{C}$ and $350^{\circ} \mathrm{C}$. The comparison of Fig. 9(a) and (b) with Fig. 9(c) and (d) shows that the hydration reaction degree of FA concrete exposed to $150^{\circ} \mathrm{C}$ was lower than that exposed to $300^{\circ} \mathrm{C}$. Fig. 9(e) and (f) show that the microstructure of the FA concrete exposed to $550^{\circ} \mathrm{C}$ was porous. Fly ash particles which had not fully hydrated were found. It can be concluded that after being exposed to temperatures of $550^{\circ} \mathrm{C}$, the orderly cycle hydration of fly ash and cement inside the FA concrete broke, which led to a sharp decrease in the splitting tensile strength of the FA concrete.

\section{CONCLUSIONS}

According to the experimental results in this paper, the effects of high temperature, cooling method, FA content and curing age on the compressive strength and splitting tensile strength of concrete with fly ash were analyzed. The following conclusions were drawn:

(1) The compressive strength and splitting tensile strength of concrete with different fly ash content after elevated temperatures tended to have a similar regularity, but the values were greatly different. The specimens cured for more than 28 days, with $20 \%$ fly ash, behaved best after being exposed to elevated temperatures. The strength of concrete with a curing age of less than 28 days reached its peak value at $150^{\circ} \mathrm{C}$, while that of FA concrete cured for more than 28 days reached its peak value at $350^{\circ} \mathrm{C}$. The strength of FA concrete aged 28 days experienced the maximum change when temperature was increased. The FA concrete 
with a curing age of 90 days was the most fire-resistant;

(2) For all curing ages, compressive strength and splitting tensile strength after exposure to elevated temperatures for FA concrete cooled by the water cooling method was lower than that of FA concrete cooled by the air cooling method. Moreover, the strength difference in FA concrete cooled by different methods was greater when exposed to higher temperatures;

(3) When the curing age was less than or equal to $28 \mathrm{~d}$, the concrete with FA content of $10 \%$ had the highest strength after being heated to high temperature. When the specimens were cured for more than 28 days, the compressive strength of the concrete with FA content of $20 \%$ was the highest after being treated at high temperature;

(4) The residual compressive strength of FA concrete after high temperature treatment increased proportionally with curing age. The increase in the compressive strength of FA concrete after high temperature at $28 \mathrm{~d}$ was more pronounced than that of the concrete without FA; and

(5) Because of the superior fire-resistance properties of fly ash, the splitting tensile strength of FA concrete exposed to elevated temperatures was higher than that of normal concrete.

\section{ACKNOWLEDGEMENTS}

The authors wish to thank the financial support by the National Natural Science Foundation of China (Grant No. 51208504).

Due to privacy and ethical concerns, neither the data nor the source of the data can be made available.

\section{REFERENCES}

[1] Wua T, Chi M and Huang R (2014) Characteristics of CFBC fly ash and properties of cement based composites with CFBC fly ash and coal fired fly ash. Construction and Building Materials 66(1):172180.

[2] Hu C (2014) Microstructure and mechanical properties of fly ash blended cement pastes. Construction and Building Materials 73:618-625.

[3] Wang X (2014) Effect of fly ash on properties evolution of cement based materials. Construction and Building Materials 69(69):32-40.

[4] Zhang F, Shen D, J. Zhou et al. (2011) Effect of thermal environment at early age on hydration phases 
composition and strength development of concrete containing fly ash. Advanced Materials Research 168170:582-588.

[5] Wang J and Yan P (2013) Evaluation of early age mechanical properties of concrete in real structure. Computers and Concrete 12(1):53-64.

[6] Wang W, Lu C, Yuan G and Zhang Y (2017) Effects of pore water saturation on the mechanical properties of fly ash. Construction and Building Materials 130:54-63.

[7] Nadeem A, Memon SA and Lo TY (2013) Evaluation of fly ash and metakaolin concrete at elevated temperatures through stiffness damage test. Construction and Building Materials 38(2):1058-1065.

[8] Li Q, Li Z and Yuan G (2012) Effects of elevated temperatures on properties of concrete containing ground granulated blast furnace slag as cementitious material. Construction and Building Materials 35(10):687-692.

[9] Nadeem A, Memon SA and Lo TY (2014) The performance of fly ash and metakaolin concrete at elevated temperatures. Construction and Building Materials 62(62):67-76.

[10] Lee SJ (2014) Mechanical properties of high performance concrete subjected to high temperature as a function of fly-ash and fiber addition. Advanced Materials Research 912-914:227-230.

[11] Shaikh FUA and Vimonsatit V (2016) Effect of cooling methods on residual compressive strength and cracking behavior of fly ash concretes exposed at elevated temperatures. Fire and Materials 40(2):335350.

[12] Jennings HM (2000) A model for the microstructure of calcium silicate hydrate in cement paste [J]. Cement and Concrete Research 30(1): 101-116.

[13] Chen B, Li C and Chen L (2009) Experimental study of mechanical properties of normal-strength concrete exposed to high temperatures at an early age. Fire Safety Journal 44(7): 997-1002.

[14] Li Q, Liu L, Huang Z and Yuan G. (2017) Residual compressive strength of cement-based grouting material with early ages after fire. Construction and Building Materials 138(5):316-325.

[15] Kocak Y and Nas S (2014) The effect of using fly ash on the strength and hydration characteristics of blended cements. Construction and Building Materials 73:25-32.

[16] Bala Murugan S, Mohan Ganesh G and Santhi AS (2014) Regression models for prediction of compressive strength of high volume fly ash concrete. Arabian Journal for Science and Engineering 39:1659-1669.

[17] Xu, G.D., Tian, Q., Miao, J.X., \& Liu, J.P. (2017). Early-age hydration and mechanical properties of 
high volume slag and fly ash concrete at different curing temperatures. Construction and Building Materials 149, 367-377.

[18] Wei, Y., Liang, S., Guo, W.Q., \& Hansen, W. (2017). Stress prediction in very early-age concrete subjected to restraint under varying temperature histories. Cement and Concrete Composites 83, 45-56.

[19] MOC (Ministry of Construction) (2011): JGJ 55-2011. Specification for mix proportion design of ordinary concrete. MOC, Beijing, China.

[20] MOC (Ministry of Construction) (2014): GB/T 50146-2014 Technical code for application of fly ash concrete. Beijing 2014.

[21] Kumar Mehta P (2004) High-performance, high-volume fly ash concrete for sustainable development. Proceedings of the International Workshop on Sustainable Development and Concrete Technology. Edited by Kejin Wang, Beijing, China, May 20-21, 2004:3-14.

[22] MOC (Ministry of Construction) (2002): GB/T 50081-2002. Standard for test method of mechanical properties on ordinary concrete. Beijing 2002.

[23] Mohamedbhai GTG (1986) Effect of exposure time and rates of heating and cooling on residual strength of heated concrete. Magazine of Concrete Research 38 (136):151-158.

[24] Liu L, Lv L, Liu Z et al. (2005) Investigation on the mechanical behavior of concrete at and after elevated temperature. Building Science 21(3):16-20（in Chinese）.

[25] Li C, Chen B and Chen L (2008) Experimental study on mechanical properties of early-aged concrete after exposure to high temperatures. Sichuan Building Science 34(4): 184-188（in Chinese）.

[26] Khan MS and Abbas H (2015) Effect of elevated temperature on the behavior of high volume fly ash concrete. Structural Engineering 19(6):1825-1831.

[27] Wang Z and Song Y (2010) Testing research of tensile and bonding strength of concrete affected by high temperature. Concrete 8:51-53 (in Chinese).

[28] Mendes A, Jay GS and Collins F (2011) Effects of slag and cooling method on the progressive deterioration of concrete after exposure to elevated temperatures as in a fire event. Materials and Structures 44(3):709-718.

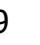

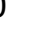




\section{LIST OF FIGURES}

FIG. 1 Variation of compressive strength of FA concrete along with temperature (a) FA0-

Cooled in the air; (b) FA0-Cooled by water; (c) FA10-Cooled in the air; (d) FA10-Cooled by water; (e) FA20-Cooled in the air; (f) FA20-Cooled by water; (g) FA30-Cooled in the air; (h) FA30-Cooled by water

FIG. 2 Effect of cooling method on the compressive strength of FA concrete: (a) FA0; (b) FA10; (c) FA20; (d) FA30

FIG. 3 Effect of the content of fly ash on compressive strength: (a) 7d-Cooled in the air; (b) 7d-Cooled by water; (c) 14d-Cooled in the air; (d) 14d-Cooled by water; (e) 28d-Cooled in the air; (f) 28d-Cooled by water; (g) 56d-Cooled in the air; (h) 56d-Cooled by water; (i) 90dCooled in the air; (j) 90d-Cooled by water

FIG. 4 Effect of the curing age on compressive strength of FA concrete: (a) FA0-Cooling in air; (b) FA0-Cooling in water; (c) FA10-Cooling in air; (d) FA10-Cooling in water; (e) FA20Cooling in air; (f) FA20-Cooling in water; (g) FA30-Cooling in air; (h) FA30-Cooling in water FIG. 5 Relation of splitting tensile strength to temperature: (a) FB0 Air Cooling; (b) FB0 Water Cooling; (c) FB20 Air Cooling; (d) FB20 Water Cooling

FIG. 6 Relation of splitting tensile strength to cooling methods; (a) FB0; (b) FB20

FIG. 7 Splitting tensile strength of concrete with and without FA at different curing ages: (a) Air Cooling; (b) Water Cooling

FIG. 8 Microstructure of 90 day specimen before being exposed to high temperature: (a) FA0; (b) FA20

FIG. 9 The microstructure of 90 day specimen after being exposed to high temperatures: (a) FA20-150 ${ }^{\circ} \mathrm{C}$ air cooling; (b) FA20 $-350^{\circ} \mathrm{C}$ air cooling; (c) FA20-150 ${ }^{\circ} \mathrm{C}$ water cooling; (d) FA20 $-350^{\circ} \mathrm{C}$ water cooling; (e) FA20 $-550^{\circ} \mathrm{C}$ air cooling; (f) FA20 $-550^{\circ} \mathrm{C}$ water cooling; 
TABLE 1 Composition of cement

\begin{tabular}{lccccccccccc}
\hline Component & $\mathrm{Na}_{2} \mathrm{O}$ & $\mathrm{MgO}$ & $\mathrm{Al}_{2} \mathrm{O}_{3}$ & $\mathrm{SiO}_{2}$ & $\mathrm{~K}_{2} \mathrm{O}$ & $\mathrm{CaO}$ & $\mathrm{Fe}_{2} \mathrm{O}_{3}$ & $\mathrm{MnO}$ & $\mathrm{TiO}_{2}$ & $\mathrm{P}_{2} \mathrm{O}_{5}$ & $\mathrm{SO}_{3}$ \\
\hline $\begin{array}{l}\text { Content } \\
(\%)\end{array}$ & 0.17 & 2.5 & 7.0 & 22.5 & 0.78 & 59 & 3.3 & 0.33 & 0.31 & 0.1 & 1.8 \\
\hline
\end{tabular}

TABLE 2 Composition of cement and fly ash

4

\begin{tabular}{llllllllllll}
\hline Component & $\mathrm{Na}_{2} \mathrm{O}$ & $\mathrm{MgO}$ & $\mathrm{Al}_{2} \mathrm{O}_{3}$ & $\begin{array}{c}\mathrm{SiO} \\
\mathrm{K}_{2} \mathrm{O}\end{array}$ & $\mathrm{CaO}$ & $\mathrm{Fe}_{2} \mathrm{O}_{3}$ & $\mathrm{MnO}$ & $\mathrm{TiO}_{2}$ & $\mathrm{P}_{2} \mathrm{O}_{5}$ & $\mathrm{SO}_{3}$ \\
\hline $\begin{array}{l}\text { Content } \\
(\%)\end{array}$ & 0.15 & 0.75 & 32.8 & 54.5 & 1.4 & 2.7 & 4.1 & 0.02 & 1.3 & 0.15 & 0.4 \\
\hline
\end{tabular}

5

6

7

TABLE 3 Material parameters of fly ash

\begin{tabular}{ccccc}
\hline Type & $\begin{array}{c}\text { Fineness ( } 45 \mu \mathrm{m} \text { square } \\
\text { hole sieve remain }) / \%\end{array}$ & $\begin{array}{c}\text { Loss of } \\
\text { ignition } / \%\end{array}$ & $\begin{array}{c}\text { Ratio of water } \\
\text { demand } / \%\end{array}$ & $\begin{array}{c}\text { Content of } \\
\text { sulphurtrioxide } / \%\end{array}$ \\
\hline Class I & 10 & 3 & 92 & 1.6 \\
\hline
\end{tabular}

8

9

TABLE 4 Mix proportion of concrete

\begin{tabular}{|c|c|c|c|c|c|c|c|}
\hline \multirow[b]{2}{*}{ Group } & \multicolumn{6}{|c|}{ Mix proportion $\left(\mathrm{kg} / \mathrm{m}^{3}\right)$} & \multirow{2}{*}{$\begin{array}{c}\text { Water } \\
\text { cement } \\
\text { ratio }\end{array}$} \\
\hline & cement & $\begin{array}{l}\text { Fly } \\
\text { ash }\end{array}$ & water & Fine aggregate & Coarse aggregate & admixture & \\
\hline FA0 & 300 & 0 & 180 & 792 & 1095 & 3 & 0.6 \\
\hline FA10 & 270 & 36 & 180 & 785 & 1095 & 3.06 & 0.59 \\
\hline FA20 & 240 & 72 & 180 & 779 & 1095 & 3.12 & 0.58 \\
\hline FA30 & 210 & 108 & 180 & 772 & 1095 & 3.18 & 0.57 \\
\hline
\end{tabular}

10 
TABLE 5 Test conditions for the concrete specimens

\begin{tabular}{|c|c|c|c|}
\hline Group of concrete & $\begin{array}{l}\text { Curing age before heating } \\
\text { (d) }\end{array}$ & Heating temperature & Cooling method \\
\hline \multirow[b]{2}{*}{$\begin{array}{c}\text { FA0、FA10、FA20、 } \\
\text { FA30 }\end{array}$} & \multirow[b]{2}{*}{ 7、14、28、56、90 } & Room temperature & - \\
\hline & & $\begin{array}{c}150^{\circ} \mathrm{C} 、 350^{\circ} \mathrm{C} 、 \\
550^{\circ} \mathrm{C}\end{array}$ & $\begin{array}{l}\text { Cooling in the air, } \\
\text { Cooling by water }\end{array}$ \\
\hline
\end{tabular}

2

3

4

TABLE 6 Compressive strength of concrete after being heated at early age(MPa)

\begin{tabular}{cccccc}
\hline $\begin{array}{c}\text { Curing age before } \\
\text { heating }\end{array}$ & $7 \mathrm{~d}$ & $14 \mathrm{~d}$ & $28 \mathrm{~d}$ & $56 \mathrm{~d}$ & $90 \mathrm{~d}$ \\
\hline
\end{tabular}

FA Temperature Air Water Air Water Air Water Air Water Air Water

\begin{tabular}{|c|c|c|c|c|c|c|c|c|c|c|c|}
\hline \multirow{4}{*}{$0 \%$} & $20^{\circ} \mathrm{C}$ & \multicolumn{2}{|c|}{17.52} & \multicolumn{2}{|c|}{26.73} & \multicolumn{2}{|c|}{32.9} & \multicolumn{2}{|c|}{34.96} & \multicolumn{2}{|c|}{37.34} \\
\hline & $150^{\circ} \mathrm{C}$ & 20.99 & 19.97 & 29.79 & 28.26 & 35.24 & 31.2 & 37.58 & 33.77 & 39.61 & 36.15 \\
\hline & $350{ }^{\circ} \mathrm{C}$ & 22.78 & 20.56 & 31.01 & 27.96 & 32.36 & 26.3 & 34.57 & 27.68 & 35.96 & 29.98 \\
\hline & $550^{\circ} \mathrm{C}$ & 14.86 & 12.65 & 22.27 & 17.75 & 24.02 & 17.84 & 27.06 & 19.91 & 27.94 & 20.79 \\
\hline \multirow{4}{*}{$10 \%$} & $20^{\circ} \mathrm{C}$ & \multicolumn{2}{|c|}{20.49} & \multicolumn{2}{|c|}{26.43} & \multicolumn{2}{|c|}{30.59} & \multicolumn{2}{|c|}{36.54} & \multicolumn{2}{|c|}{42.85} \\
\hline & $150^{\circ} \mathrm{C}$ & 21.82 & 20.55 & 28.27 & 26.51 & 33.87 & 30.85 & 36.77 & 33.52 & 43.02 & 39.18 \\
\hline & $350^{\circ} \mathrm{C}$ & 20.07 & 17.86 & 25.9 & 23.02 & 35.13 & 31.51 & 40.72 & 36.76 & 45.26 & 40.28 \\
\hline & $550{ }^{\circ} \mathrm{C}$ & 16.15 & 13.54 & 20.6 & 17.34 & 25.57 & 21.97 & 30.52 & 26.48 & 36.64 & 31.14 \\
\hline \multirow{4}{*}{$20 \%$} & $20^{\circ} \mathrm{C}$ & \multicolumn{2}{|c|}{14.84} & \multicolumn{2}{|c|}{22.07} & \multicolumn{2}{|c|}{27.96} & \multicolumn{2}{|c|}{39.71} & \multicolumn{2}{|c|}{45.48} \\
\hline & $150^{\circ} \mathrm{C}$ & 16.24 & 15.11 & 23.61 & 21.94 & 32.35 & 29.27 & 39.88 & 36.97 & 46.01 & 42.56 \\
\hline & $350^{\circ} \mathrm{C}$ & 14.56 & 12.71 & 20.95 & 18.44 & 33.24 & 30.011 & 44.33 & 39.8 & 49.92 & 44.71 \\
\hline & $550^{\circ} \mathrm{C}$ & 11.13 & 9.23 & 16.82 & 13.93 & 24.88 & 21.31 & 35.17 & 29.83 & 38.98 & 33.16 \\
\hline \multirow{4}{*}{$30 \%$} & $20^{\circ} \mathrm{C}$ & \multicolumn{2}{|c|}{10.45} & \multicolumn{2}{|c|}{18.31} & \multicolumn{2}{|c|}{25.88} & \multicolumn{2}{|c|}{32.6} & \multicolumn{2}{|c|}{39.95} \\
\hline & $150^{\circ} \mathrm{C}$ & 11.98 & 11.03 & 20.52 & 18.89 & 28.87 & 26.35 & 33.78 & 31.01 & 40.25 & 37.04 \\
\hline & $350^{\circ} \mathrm{C}$ & 10.27 & 8.91 & 17.5 & 15.23 & 30.36 & 27.02 & 35.15 & 31.62 & 42.14 & 38.01 \\
\hline & $550^{\circ} \mathrm{C}$ & 7.69 & 6.32 & 13.38 & 10.97 & 22.78 & 19.36 & 27.94 & 23.31 & 32.76 & 27.18 \\
\hline
\end{tabular}

5

6

7

8

9

10 
TABLE 7 Splitting strength of FA concrete after being heated at early age (MPa)

\begin{tabular}{|c|c|c|c|c|c|c|c|c|c|c|c|}
\hline Age & & $7 d$ & & $14 d$ & & $28 \mathrm{~d}$ & & $56 \mathrm{~d}$ & & $90 d$ & \\
\hline \multirow{2}{*}{$\begin{array}{l}\text { Fly ash } \\
\text { content }\end{array}$} & \multirow{2}{*}{$\begin{array}{l}\text { Temperature } \\
\left({ }^{\circ} \mathrm{C}\right)\end{array}$} & \multicolumn{10}{|c|}{ Cooling method } \\
\hline & & Air & Water & Air & Water & Air & Water & Air & Water & Air & Water \\
\hline \multirow{4}{*}{$0 \%$} & 20 & 1.93 & & 2.95 & & 3.63 & & 3.91 & & 4.26 & \\
\hline & 150 & 2.32 & 2.2 & 3.29 & 3.12 & 3.8 & 3.38 & 4.17 & 3.75 & 4.5 & 4.03 \\
\hline & 350 & 2.51 & 2.27 & 3.42 & 3.09 & 3.51 & 2.81 & 3.75 & 3.04 & 4.09 & 3.27 \\
\hline & 550 & 1.61 & 1.4 & 2.46 & 1.96 & 2.79 & 1.99 & 2.48 & 1.71 & 2.93 & 2.01 \\
\hline \multirow{4}{*}{$20 \%$} & 20 & 1.64 & & 2.44 & & 2.71 & & 4.02 & & 4.92 & \\
\hline & 150 & 1.79 & 1.67 & 2.61 & 2.42 & 3.09 & 2.86 & 4.31 & 4.06 & 4.97 & 4.61 \\
\hline & 350 & 1.61 & 1.4 & 2.31 & 2.04 & 3.25 & 2.89 & 4.45 & 3.91 & 5.05 & 4.58 \\
\hline & 550 & 1.23 & 1.02 & 1.86 & 1.54 & 2.13 & 1.77 & 2.97 & 2.52 & 3.94 & 3.34 \\
\hline
\end{tabular}




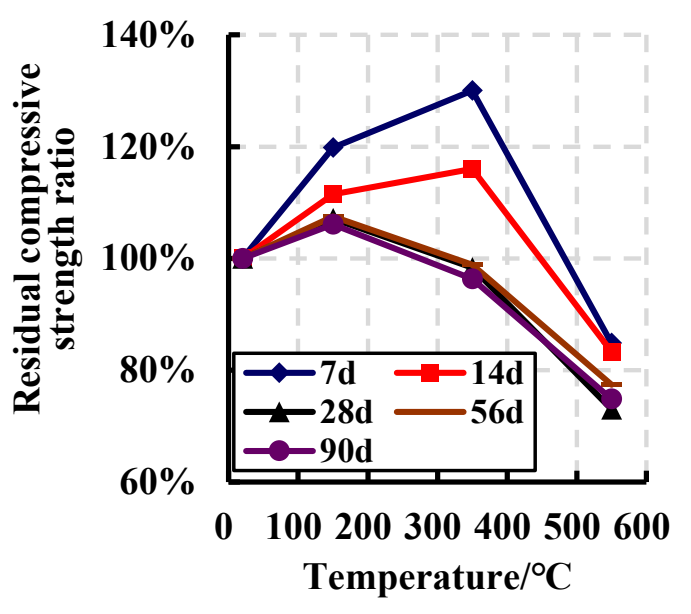

(a)

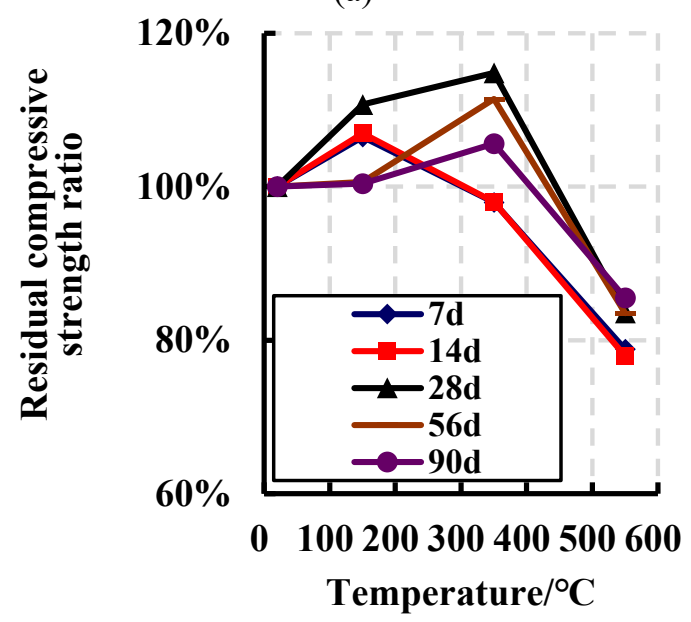

(c)

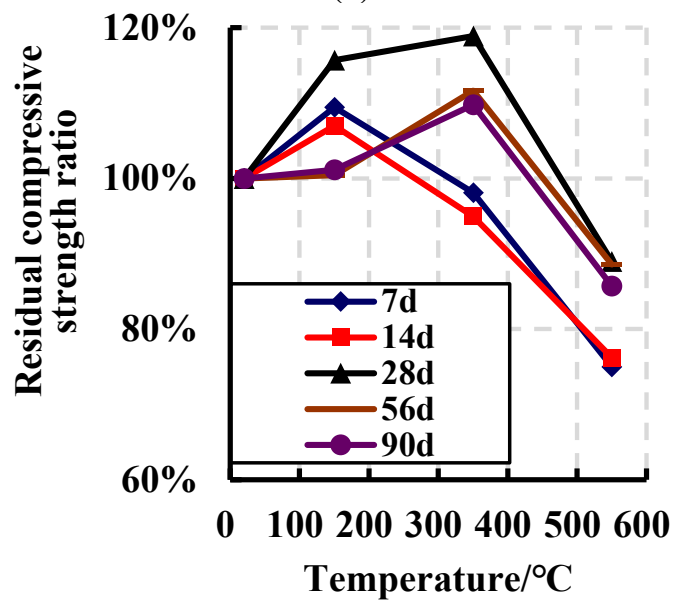

(e)

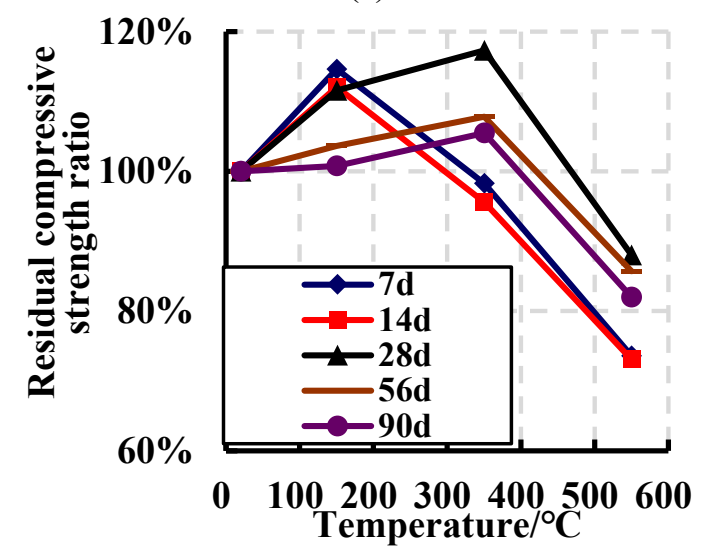

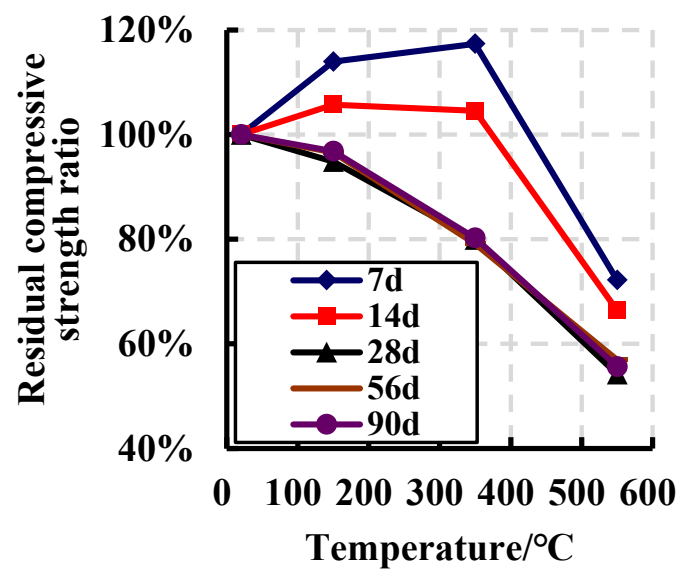

(b)

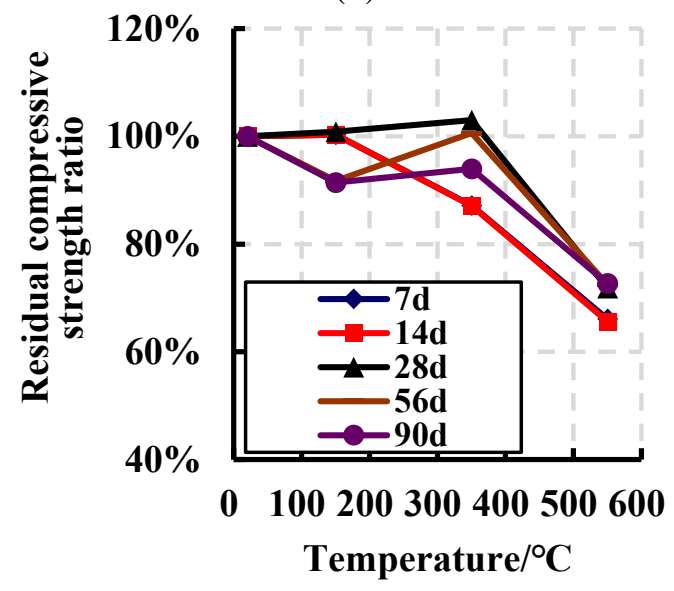

(d)

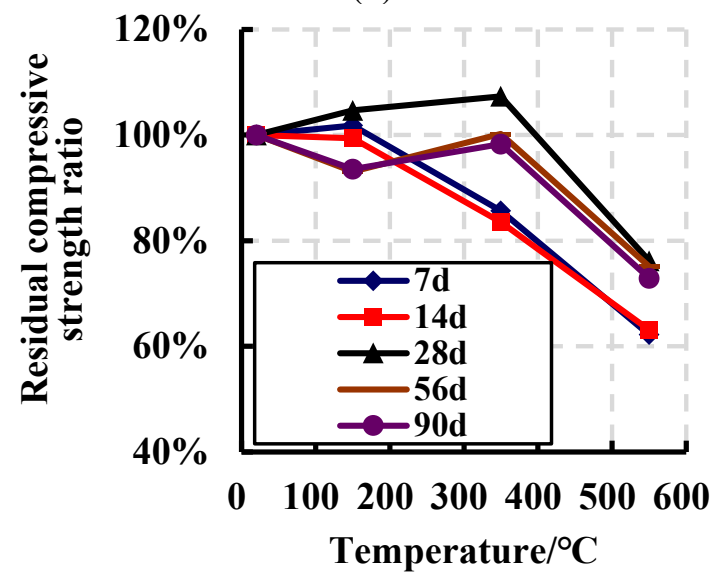

(f)

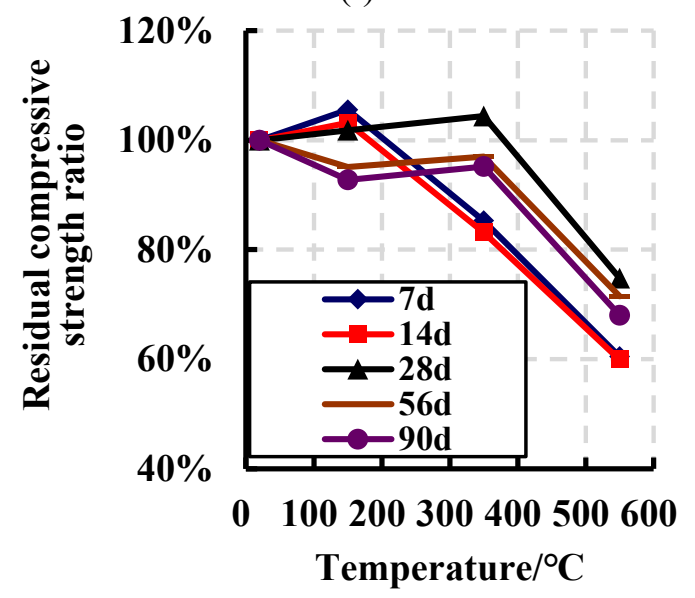

(h) 


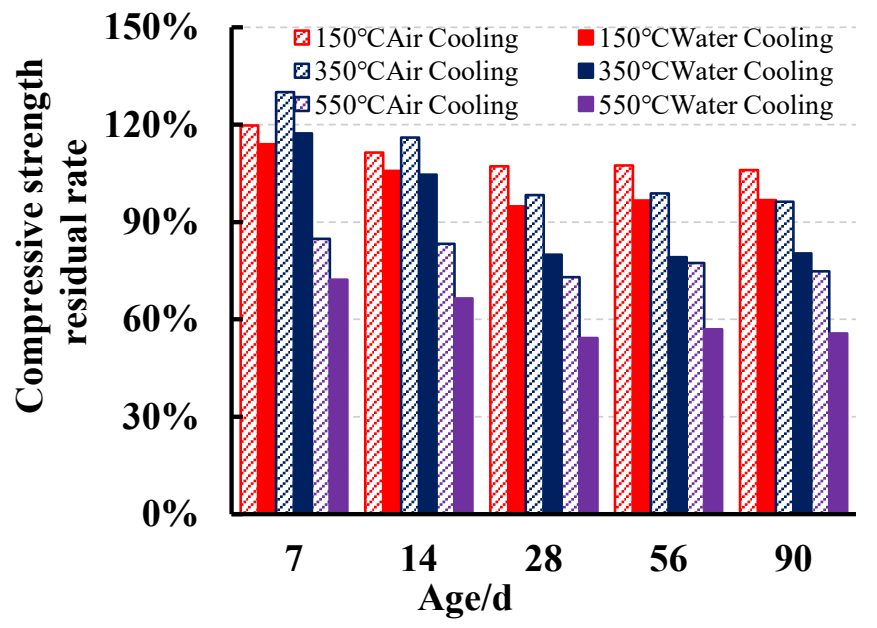

(a)

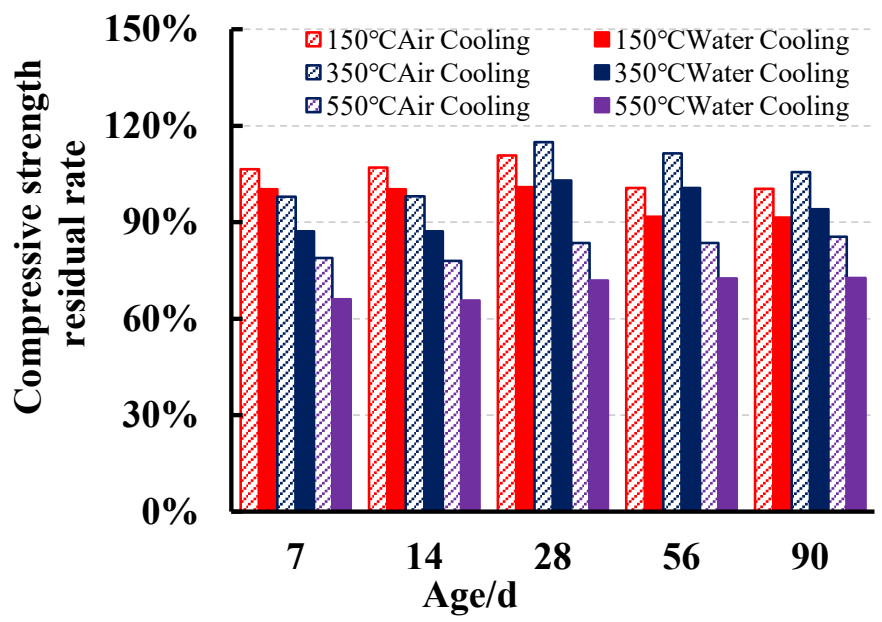

(b)

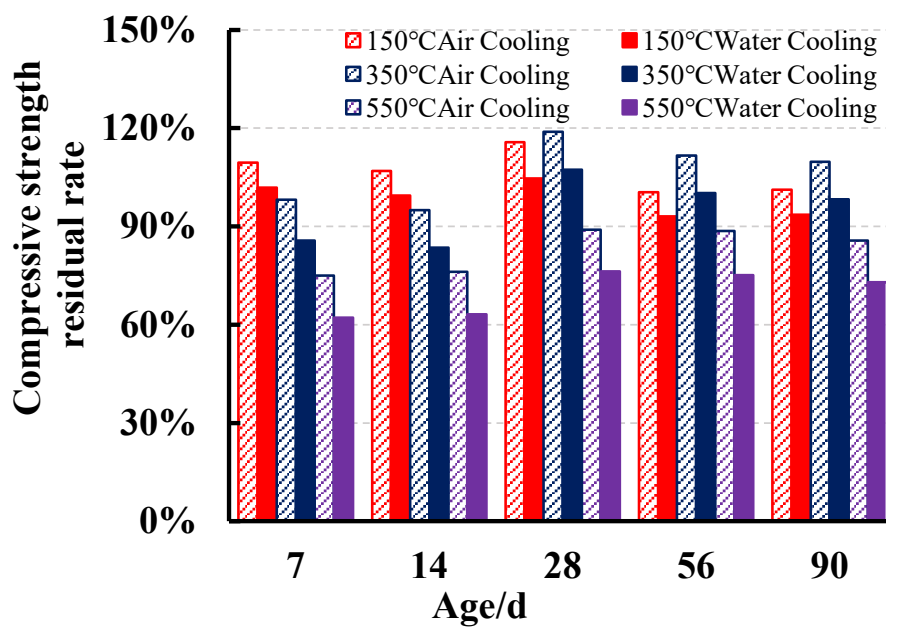

(c)

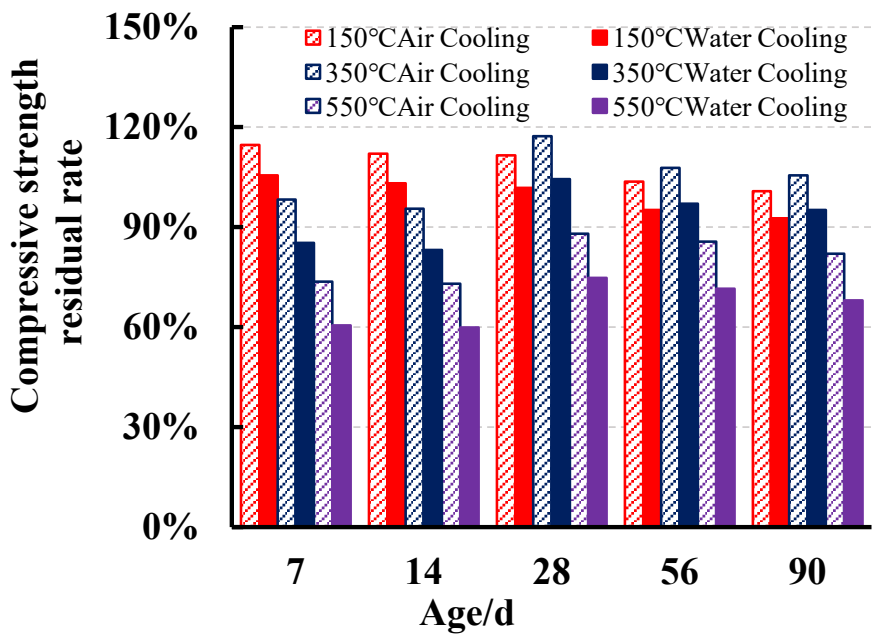

(d) 


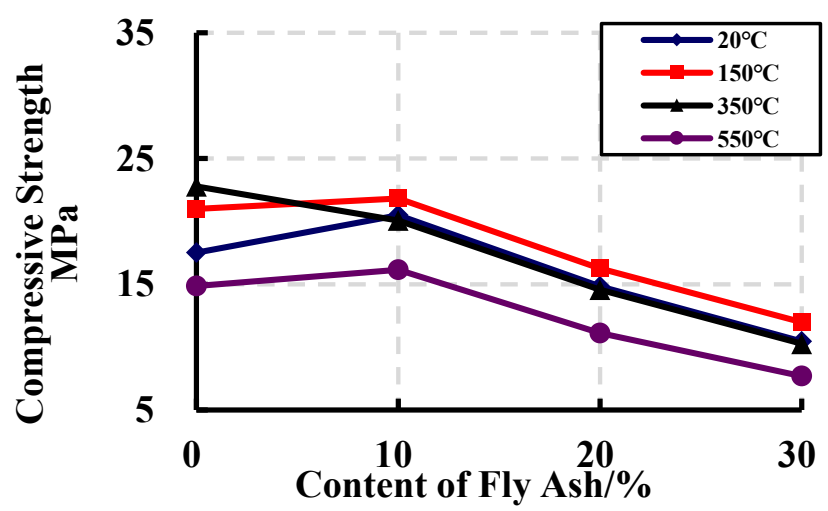

(a)

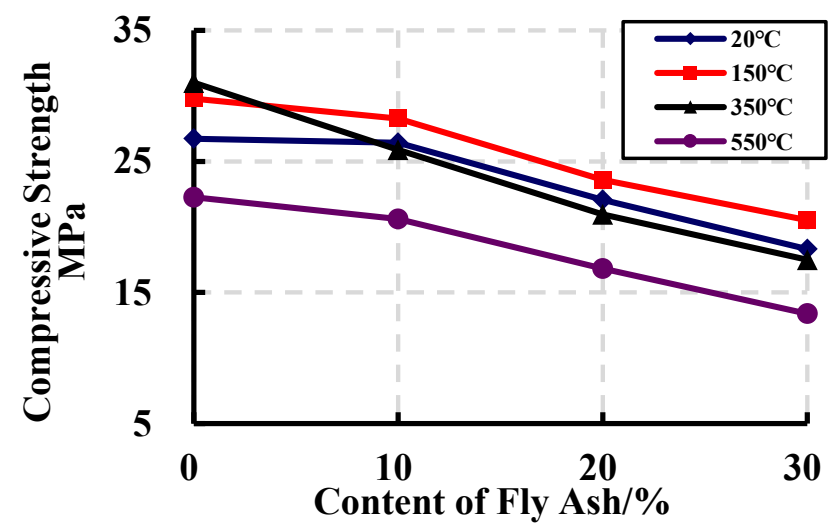

(c)

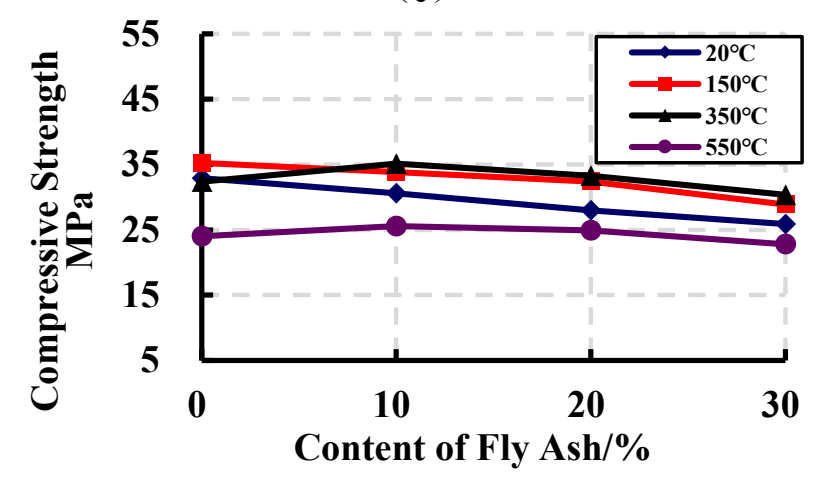

(e)

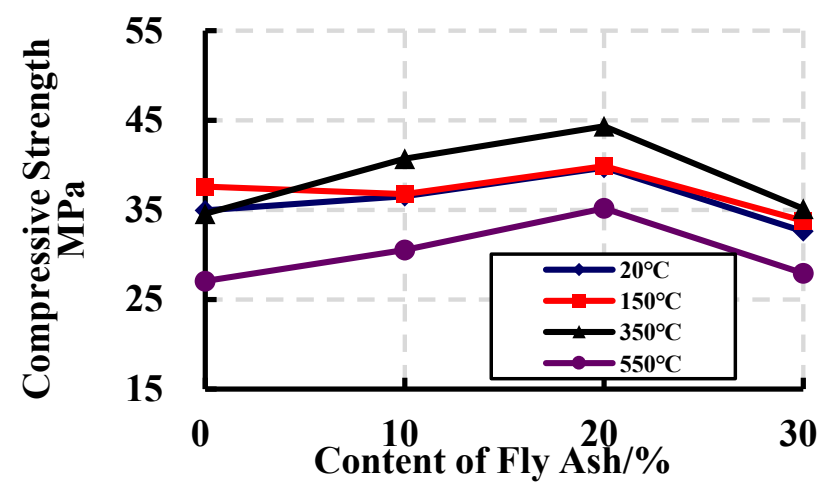

(g)

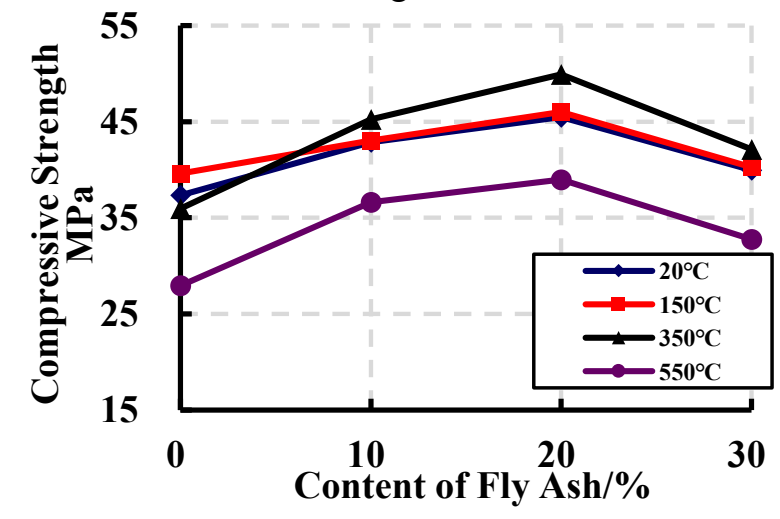

(i)

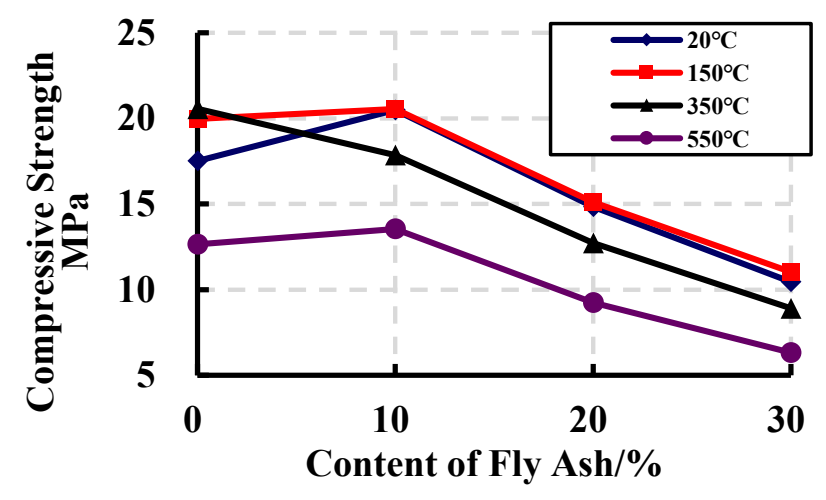

(b)

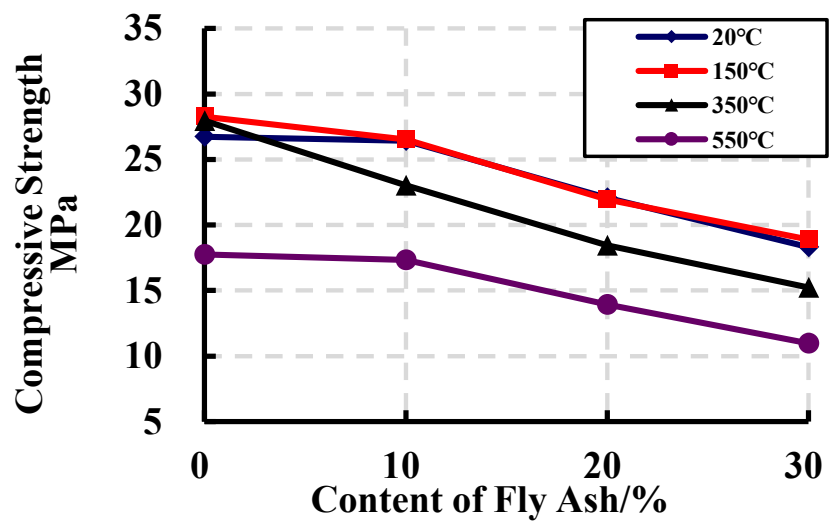

(d)

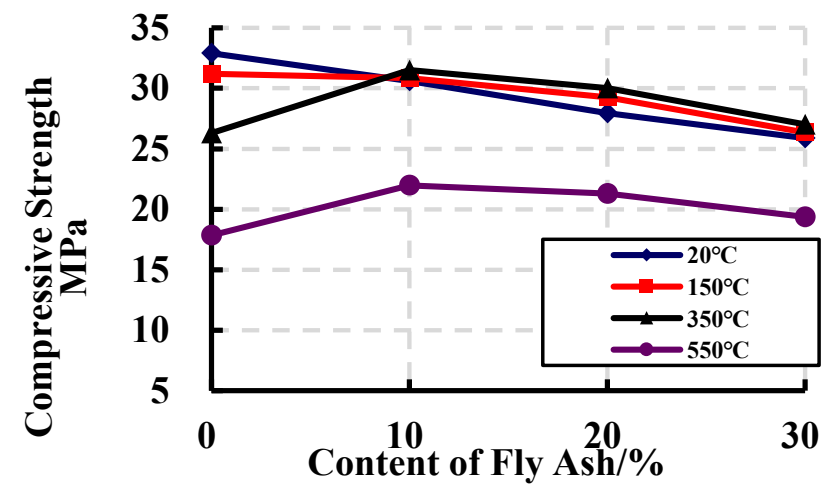

(f)

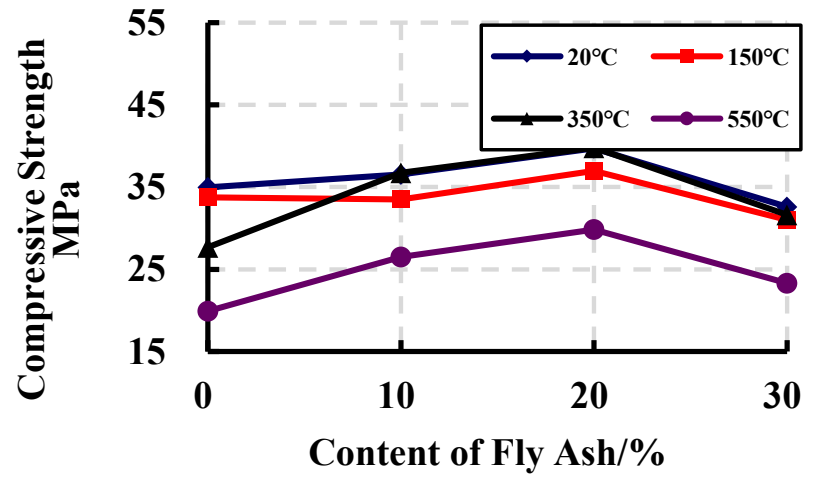

(h)

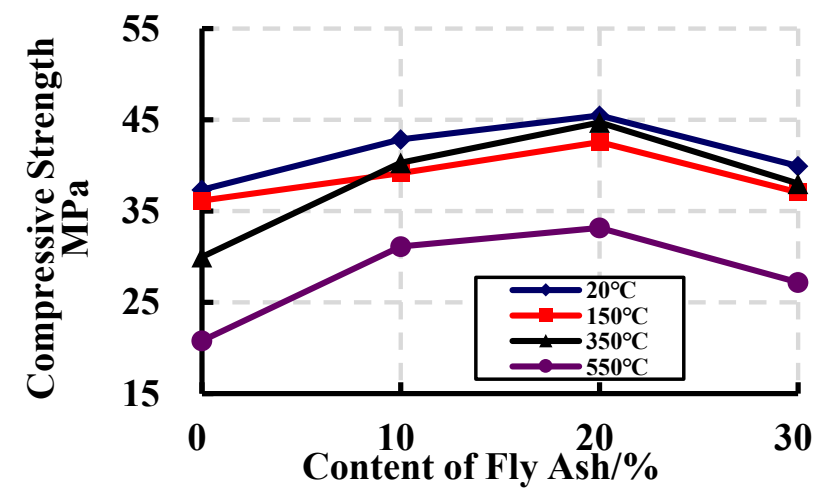

(j) 


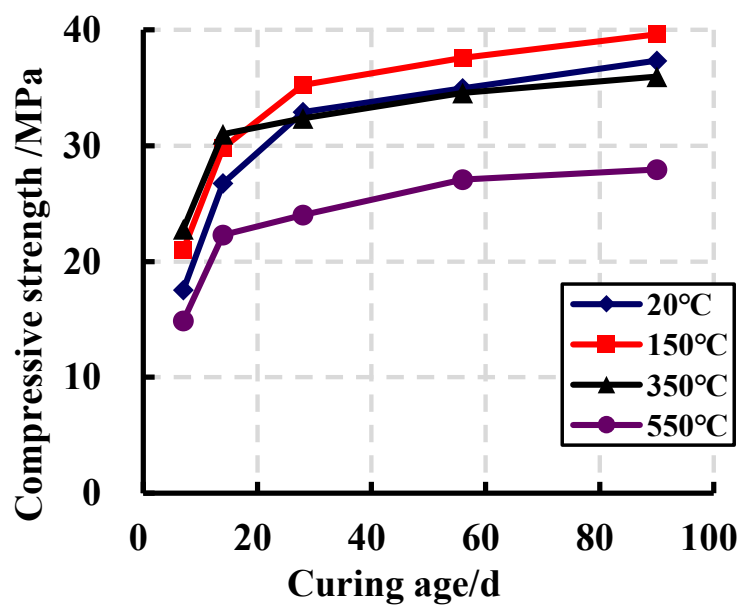

(a)

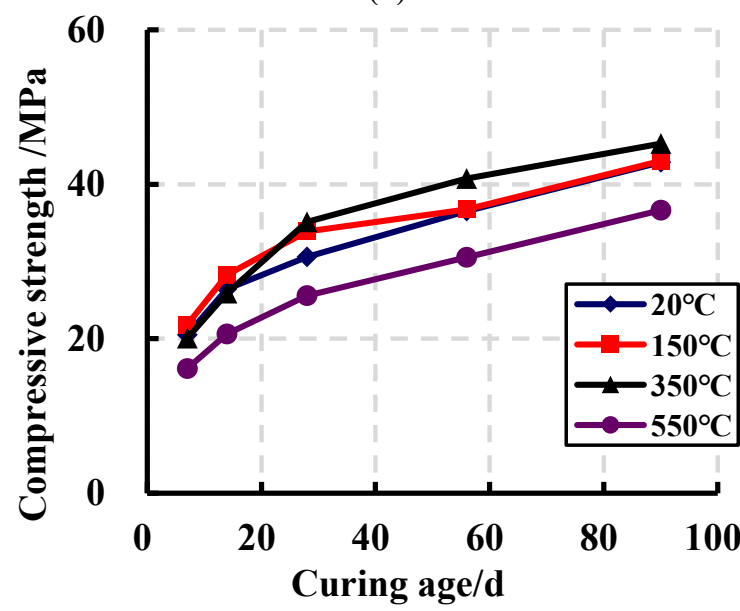

(c)

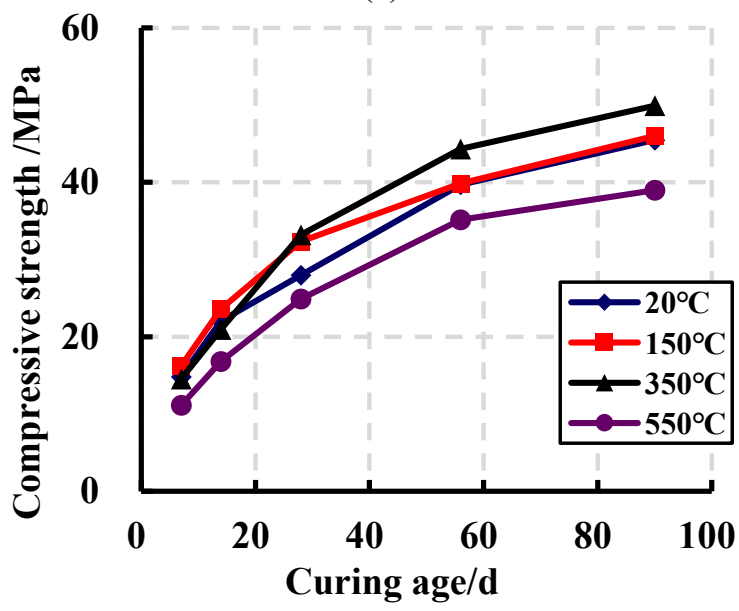

(e)

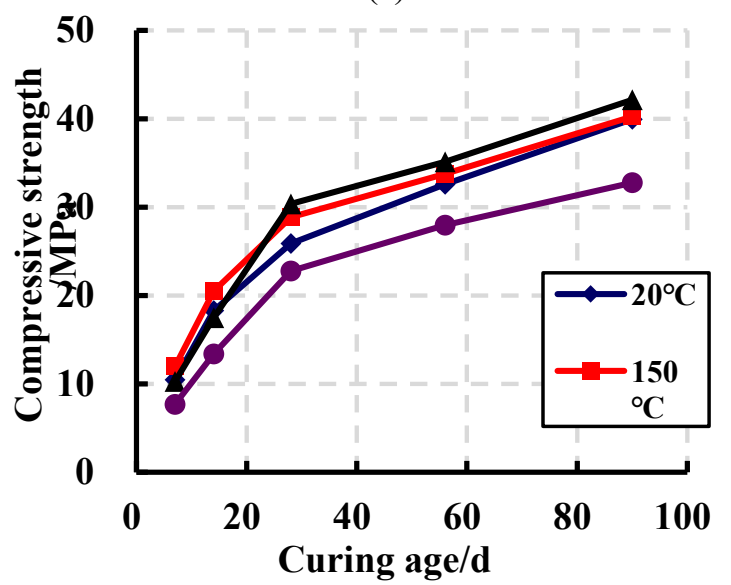

(g)

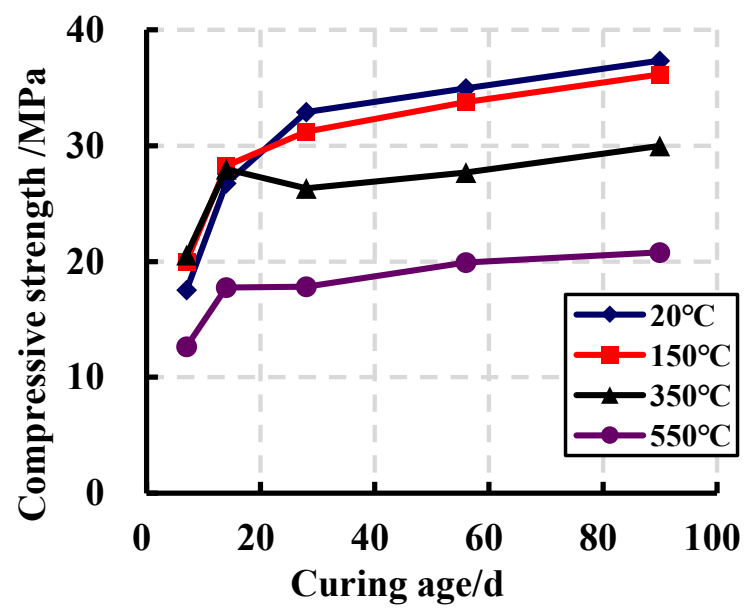

(b)

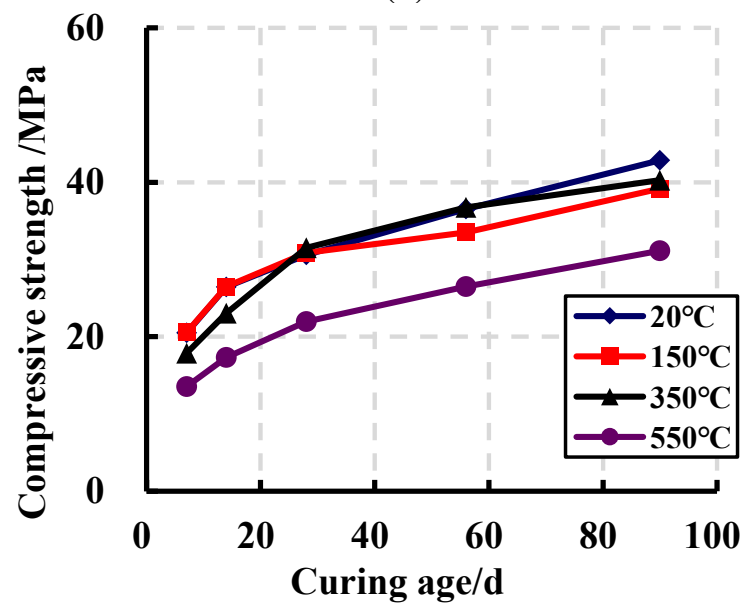

(d)

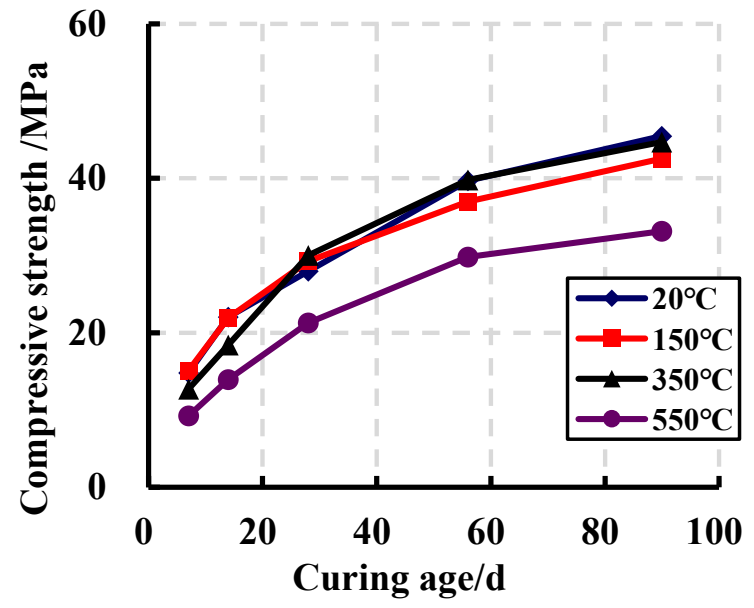

(f)

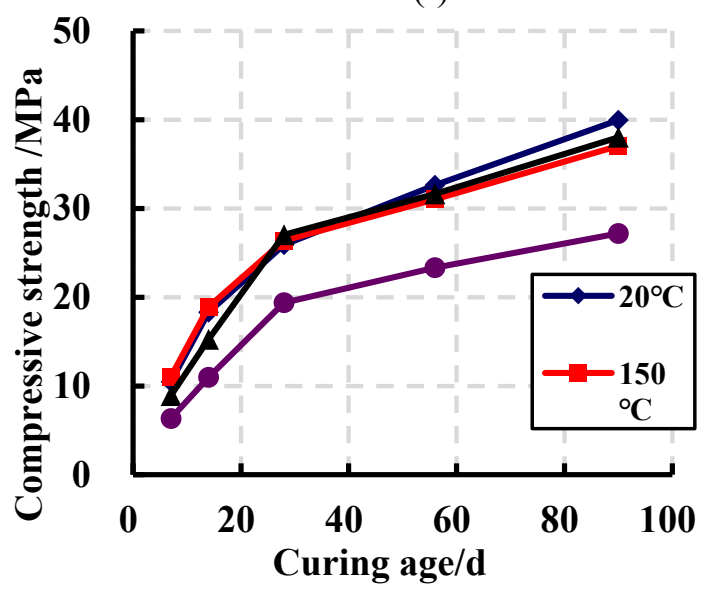

(h) 


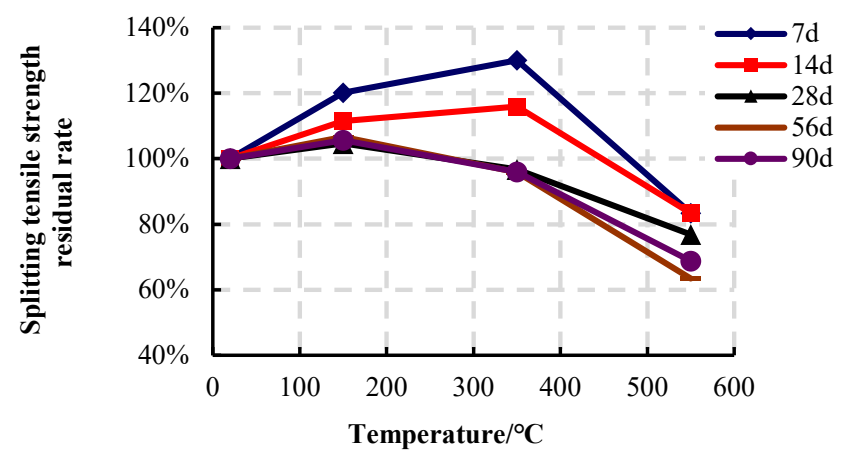

(a)

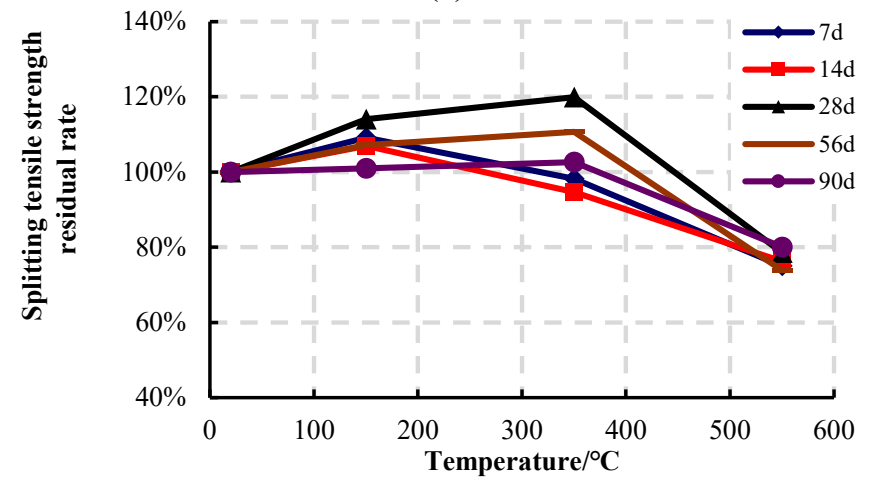

(c)

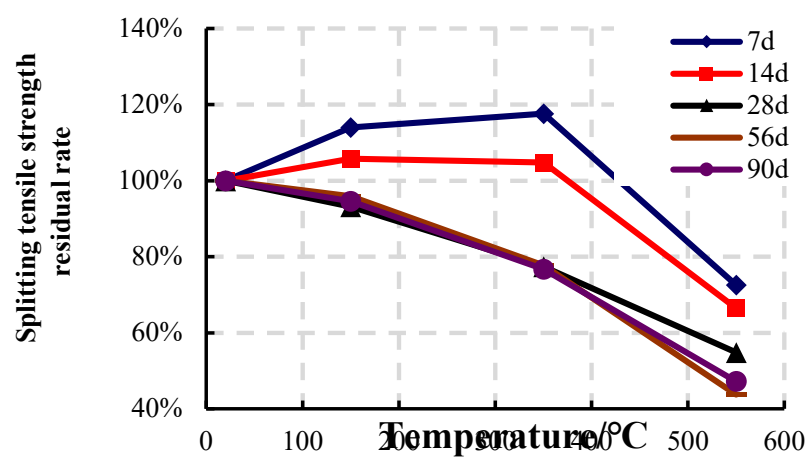

(b)

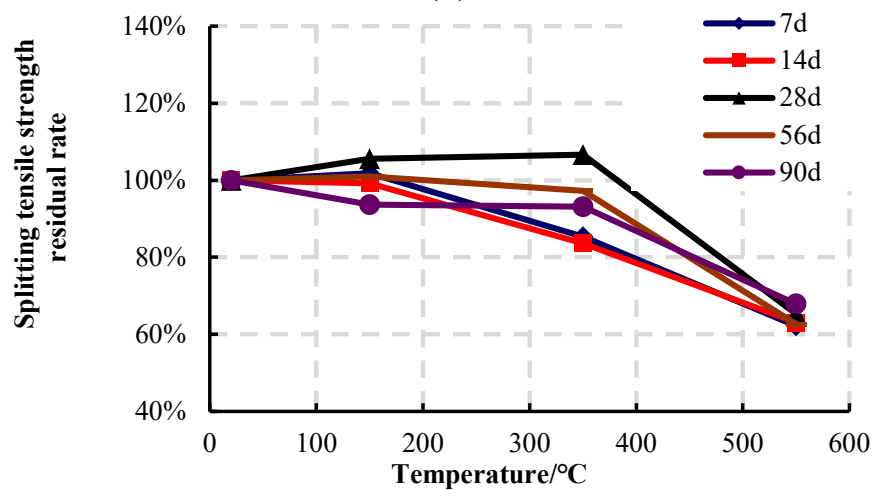

(d)

Fig. 5 Relation of splitting tensile strength to temperature 


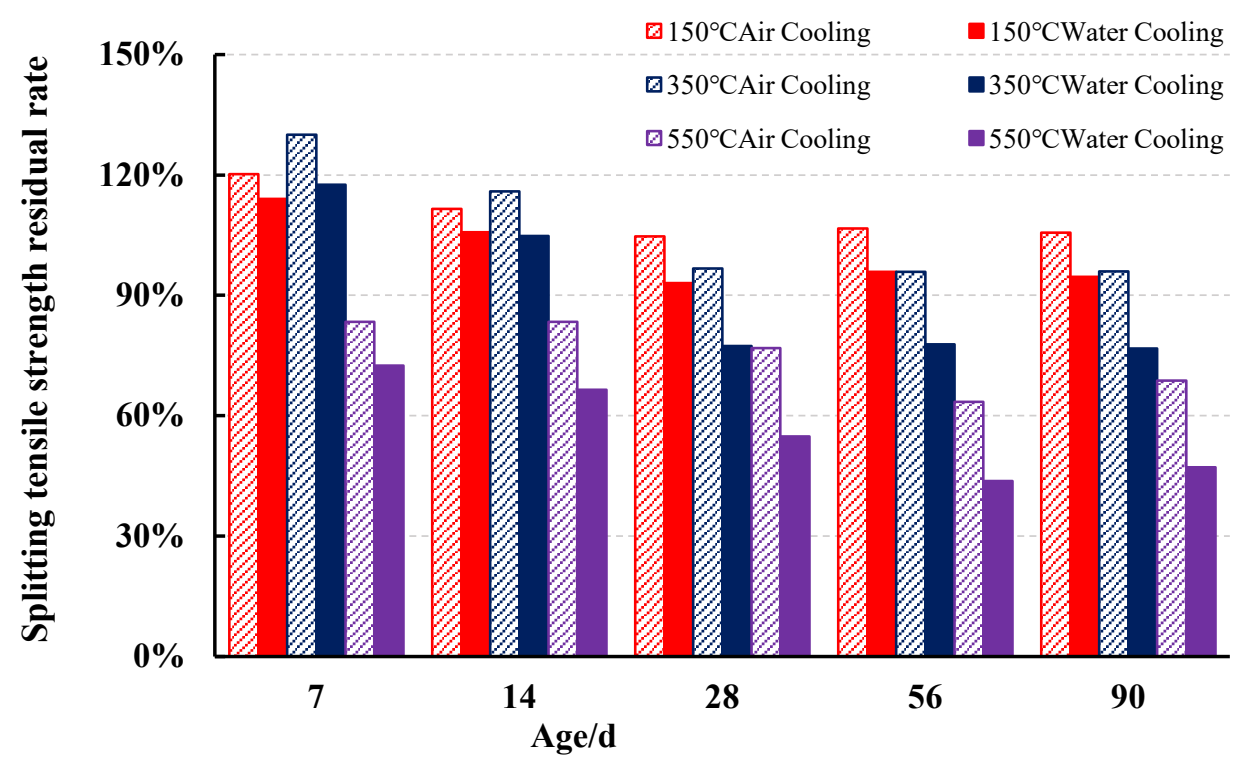

(a)

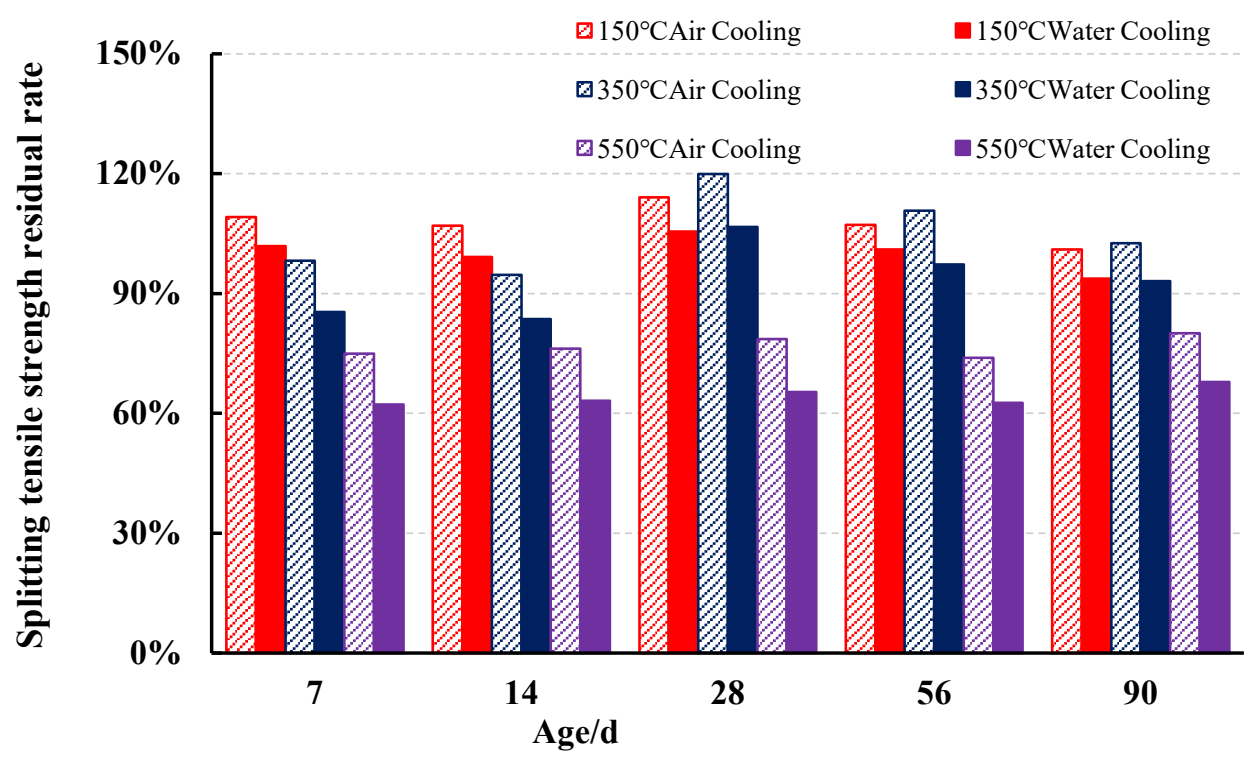

(b)

Fig. 6 Relation of splitting tensile strength to cooling methods 


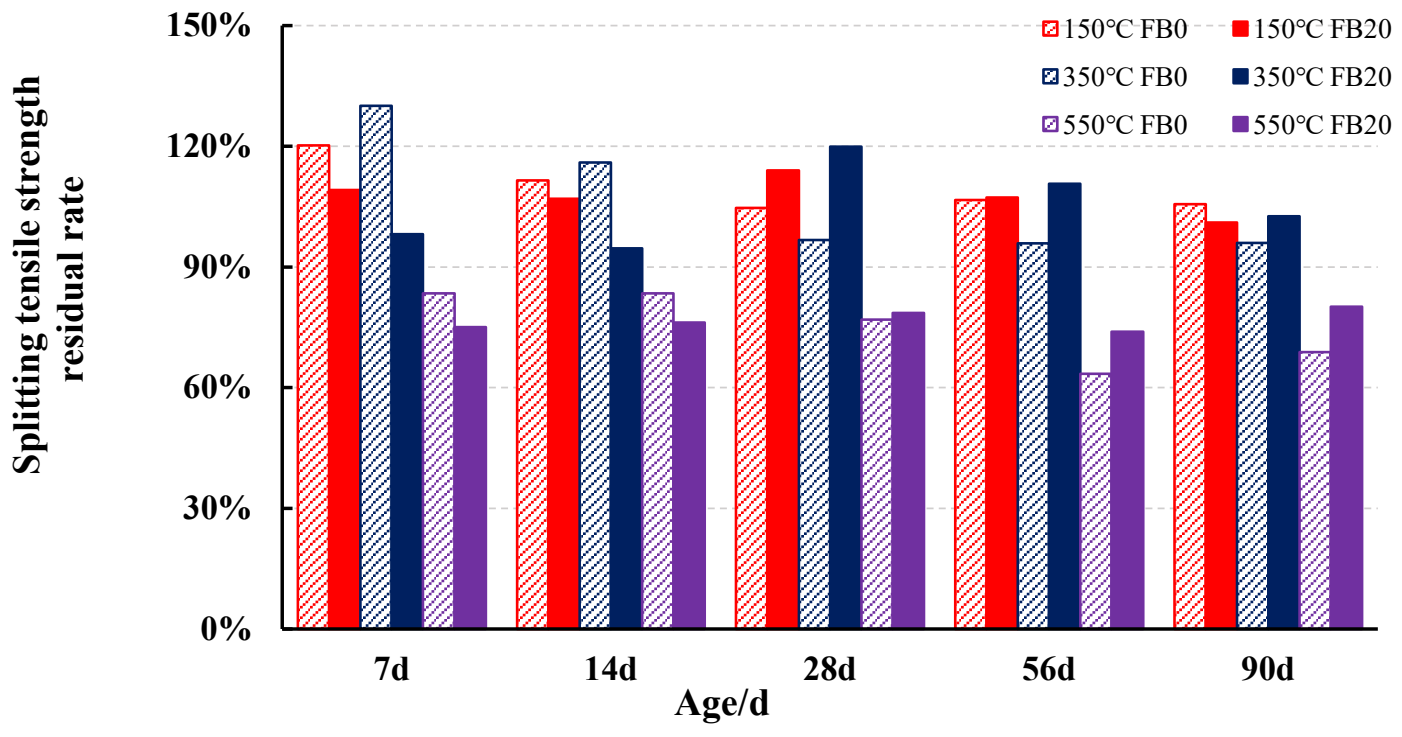

(a)

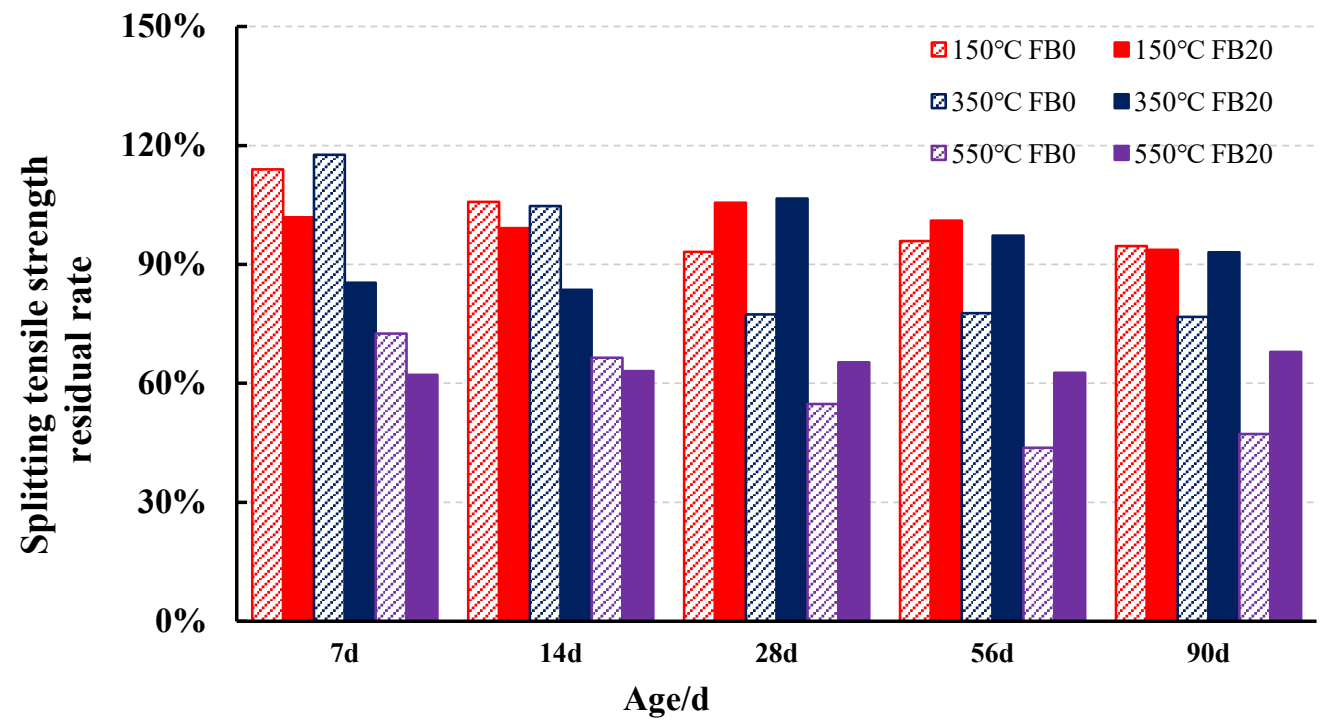

(b)

Fig.7 Splitting tensile strength of concrete with and without FA at different curing ages 


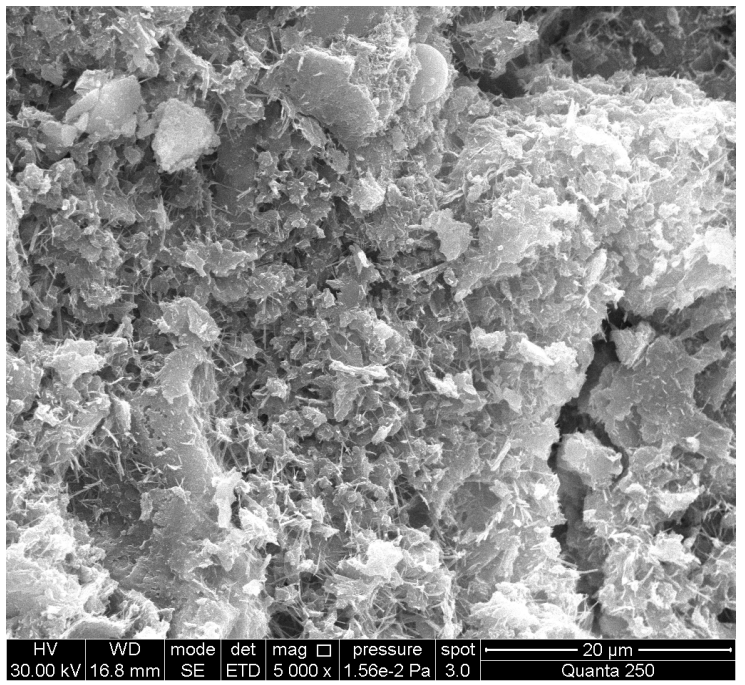

(a)

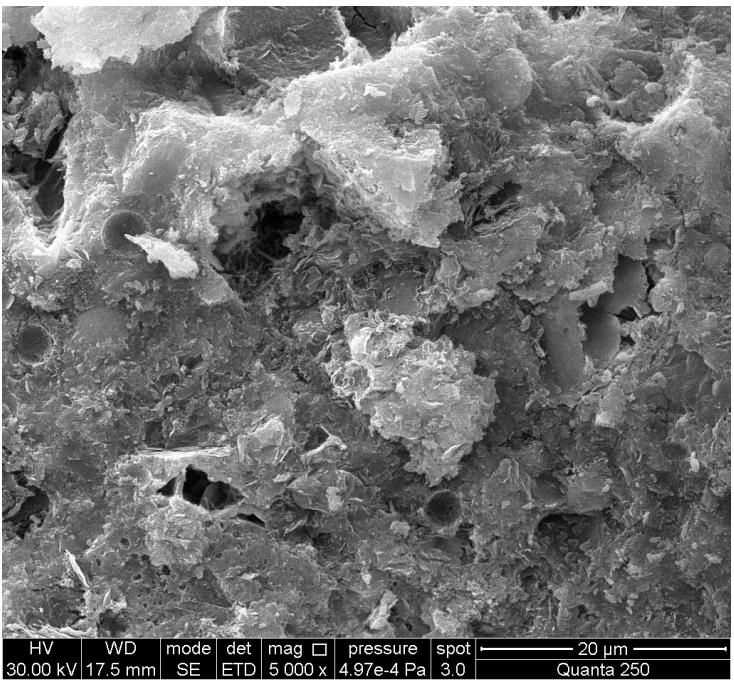

(b)

Fig. 8 Microstructure of 90 day specimen before being exposed to high temperature 


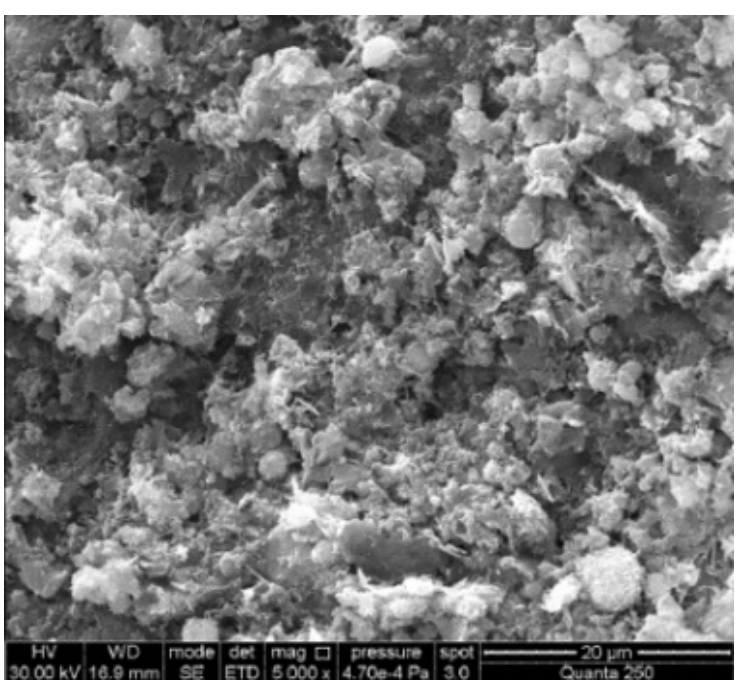

(a)

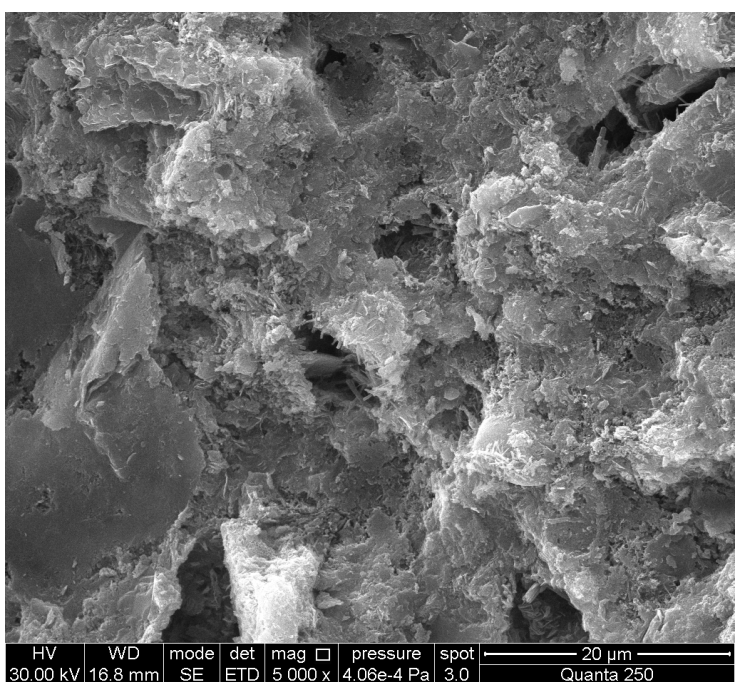

(c)

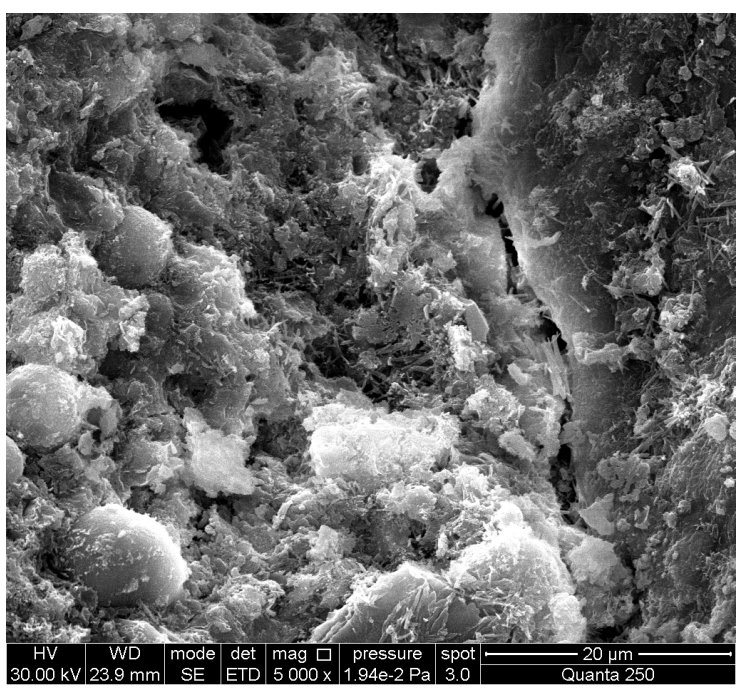

(e)

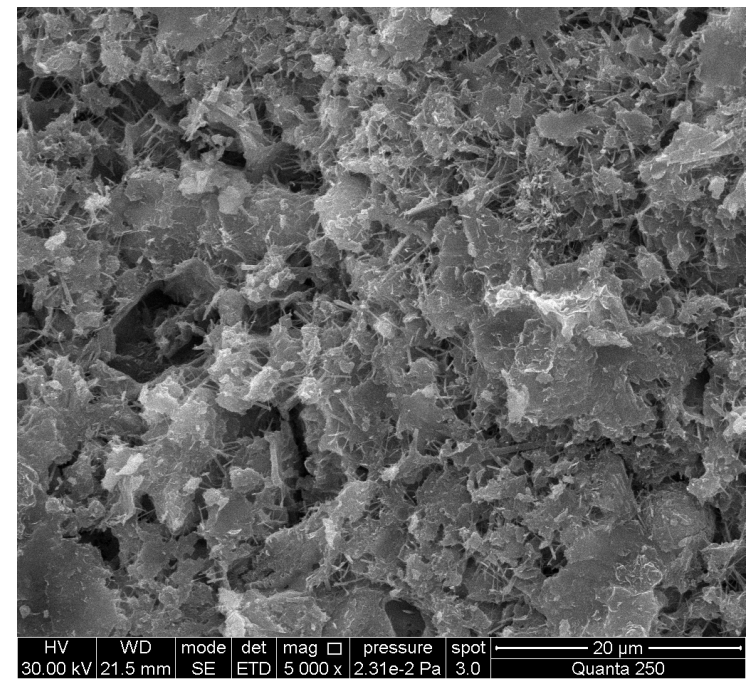

(b)

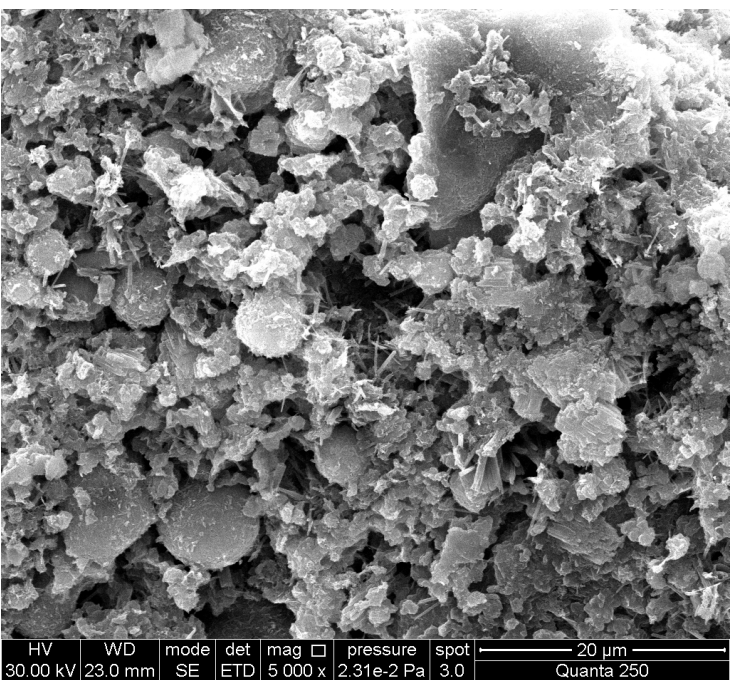

(d)

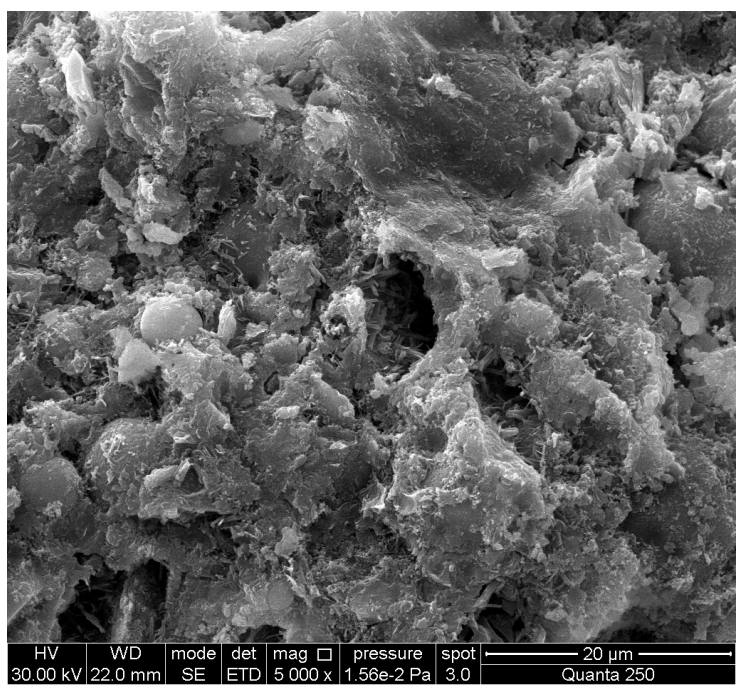

(f)

Fig. 9 The microstructure of 90 day specimen after being exposed to high temperatures 